The role of thermostatic radiator valves for the control of space heating in UK social-rented households

\title{
Bruce-Konuah, Adorkor
}

http://hdl.handle.net/10026.1/11625

10.1016/j.enbuild.2018.05.023

Energy and Buildings

Elsevier

All content in PEARL is protected by copyright law. Author manuscripts are made available in accordance with publisher policies. Please cite only the published version using the details provided on the item record or document. In the absence of an open licence (e.g. Creative Commons), permissions for further reuse of content should be sought from the publisher or author. 


\title{
The role of thermostatic radiator valves for the control of space heating in UK social-rented households
}

Adorkor Bruce-Konuaha ${ }^{\star}$, Rory V. Jones ${ }^{a}$, Alba Fuertes ${ }^{a}$, Leonardo Messi ${ }^{b}$, Alberto Girettib

a Department of Architecture and Built Environment, University of Plymouth, Drake Circus, Plymouth, Devon, PL4 8AA, UK.

b Department of Civil Engineering and Architecture, Università Politecnica delle Marche, Via delle Brecce Bianche, 60100 Ancona, Italy.

Email addresses: adorkor.bruce@plymouth.ac.uk (A. Bruce-Konuah), rory.jones@plymouth.ac.uk (R.V. Jones), alba.fuertes@plymouth.ac.uk (A. Fuertes), I.messi@staff.univpm.it (L. Messi), a.giretti@staff.univpm.it (A. Giretti)

Corresponding author*.

Tel.: +44(0)1752 585173; Fax: +44(0)1752 585155

\begin{abstract}
This paper provides an analysis of the relationships between dwelling, household and motivation, behaviour and perception characteristics and thermostatic radiator valve (TRV) settings in living rooms $(n=187)$ and bedrooms $(n=159)$ in UK social housing. The work capitalises on primary data from a sociotechnical household survey undertaken in Plymouth, UK during 2015, which was coupled with building audit data. The mean reported TRV setpoint temperatures in the living rooms and bedrooms were $23.4^{\circ} \mathrm{C}$ and $21.9^{\circ} \mathrm{C}$, implying that occupants prefer cooler conditions in bedrooms. There were systematic variations according to dwelling, household, and motivation, behaviour and perception characteristics. In general, the setpoint temperatures in individual rooms were higher than the whole house thermostat setpoint temperature, implying that there may be a misunderstanding of the role of TRVs in the home heating system. The research could enable social housing providers, the government and commercial organisations to target energy efficiency measures (i.e. thermal upgrades) and social interventions (i.e. behaviour change) at those dwellings and households where their impact may be most beneficial. The results presented could also be used to improve the assumptions of zonal heating behaviour in energy models, which could result in more realistic predictions of the heating demands of social housing.
\end{abstract}

Keywords: Thermostatic radiator valve, Space heating preferences, Social housing, Heating setpoint temperature, Socio-technical survey

Abbreviations: TRV, Thermostatic Radiator Valve; BREDEM, Building Research Establishment Domestic Energy Model; HRP, Household Representative Person

\section{Introduction}

In the UK, the domestic sector is responsible for about a quarter of the UK's greenhouse gas (GHG) emissions, with space heating alone resulting in $11 \%$ of the nation's emissions [1]. These figures make it clear that it will be impossible to meet the UK's legally binding carbon reduction target of $80 \%$ by 2050 compared to 1990 levels [2] without reducing emissions from homes, and in particular those associated with space heating. 
Before 1970, the majority of UK homes were heated using solid fuels such as coal. By the 1980s, central heating was regarded as a basic requirement, and now, for over $90 \%$ of homes, a gas-fired central heating system [3] is the predominant type of space heating. Gas central heating systems are more efficient than fuels such as coal and have resulted in greater carbon efficiency for heating. In the 2005 amendment to the Building Regulations, it was mandated that the seasonal efficiency of boilers in the UK should be at least $86 \%$ [4] to further improve the energy and carbon efficiency of home heating systems.

The installation of central heating has resulted in homes now being heated at significantly higher temperatures (approximately $4^{\circ} \mathrm{C}$ warmer) during winter compared to 40 years before [5]. This has been coupled with changes in occupants' aspirations about how warm their homes should be, as well as expectations about how these increased temperatures should be achieved [6]. Furthermore, central heating systems have made it possible for households to heat all of the spaces within their homes ${ }^{1}$. This has resulted in an increase in the amount of energy used for space heating. A basic central heating system consists of a central boiler, a pump and individual radiators installed in multiple spaces throughout a dwelling. Water is heated by the boiler using natural gas and is pumped from the boiler to each radiator where the heat is emitted into the rooms. Most central heating systems will also have some level of controls. A full set of central heating controls consist of a central timer, a room thermostat and thermostatic radiator valves (TRVs). The TRVs enables zonal heating control.

In the UK, since 2010, two zone heating control has been mandatory for every new dwelling which is not open plan [7], however this is not obligatory in existing dwellings. A central heating system which is in compliance with Building Regulation Part L1B will have the full set of controls. The room thermostat is used to set a heating demand temperature below which the boiler is activated to heat and pump water through the dwelling and above which the boiler is switched off. The timer is used to set the times at which the heating system will turn on and off, hence setting the heating duration. Even when a timer is used to control the duration of the heating period, the boiler will be turned off when the demand temperature is attained. The TRVs provide a degree of temperature control in individual rooms by adjusting the water flow through the radiators and controlling its heat output.

Even with the widespread ownership of central heating systems in UK homes, it is reported that about $70 \%$ of the housing stock do not have the full set of heating controls specified in the building regulations [8]. The report suggests that of all homes with a boiler (approx. 20.6 million homes), 38\% do not have a whole house thermostat and $45 \%$ do not have TRVs. A dwelling with no thermostat will result in excessive room temperatures and no TRVs means that there is no zonal temperature control. Unnervingly, $4 \%$ of all homes with a boiler do not have any controls at all. Research has shown that in addition to external temperature and building fabric, the key factors that influence a dwelling's space heating energy demand are the heating system's thermostat and timer settings chosen by the occupants (where such controls are available) [9]-[12].

Several studies have shown that dwelling characteristics (e.g. type, age, number of habitable rooms, etc.), household socio-demographics (e.g. size, composition, health status, etc.), and occupant's motivations, behaviours and perceptions (e.g. affordability of energy bills, perceived control over energy use, heating related behaviours, etc.) affect heating demand temperatures and heating durations and thus heating use in homes [12]-[23]. Wei et al. [24] provide a detailed review and discussion of the key factors that influence households' space heating behaviour.

In buildings, occupants interact with the available heating controls to maintain a level of comfort. It should be noted that simply providing central heating controls does not necessarily result in homes being heated in ways that reduce energy consumption and carbon emissions [9]. In fact, previous research has shown that some households do not realise they have heating controls and that there is limited understanding of the purpose of the different controls [25].

\footnotetext{
${ }^{1}$ Before central heating only living rooms and bedrooms were normally heated by a solid fuel fireplace, spaces such as corridors, bathrooms and kitchens were unheated.
} 
As well as thermostats and timers/programmers, many households also have TRVs fitted to each individual radiator in their home. TRVs allow for temperatures in individual rooms to be controlled (i.e. zonal control). This implies that different, lower setpoint temperatures than the whole house thermostat can be set for different rooms within a dwelling. TRVs have the potential to reduce the energy used for space heating, as heating demand temperatures in less frequently occupied rooms or rooms requiring cooler temperatures can be reduced and heating in unoccupied rooms can be turned off completely. In order to support decisions to help reduce space heating energy demand in social housing, it is important to understand the role of TRVs and how social housing tenants currently use them.

Past literature on occupants' choice of space heating demand temperatures have primarily focussed on the whole house thermostat setting (e.g. [9], [11], [26], [27]. Furthermore, Jones et al.'s [12] literature review on domestic energy modelling studies showed that most often, the same setpoint temperature (i.e. the whole house thermostat setting) was used for all building zones (e.g. living rooms, bedroom, kitchens, etc.), despite, studies measuring indoor temperatures in living rooms and bedrooms showing that bedrooms are often kept cooler. These studies highlight the role of TRV settings [9], [11], [26] in defining cooler zonal temperatures, but currently the factors influencing TRV settings have not been investigated.

This paper aims to address this gap in knowledge and provide an insight into the use of TRVs in living rooms and bedrooms in UK social housing and to understand the effects of dwelling, household and motivation, behaviour and perception characteristics on the choice of TRV setpoint temperatures. The study will also provide a comparison between TRV and whole house thermostat setpoint temperatures to understand how occupants are using the available heating controls to control their thermal comfort in UK social housing.

The work reported in this paper capitalises on primary data collected during a socio-technical household survey, undertaken in Plymouth, UK, during 2015, which was merged with building audit records held by the social housing association managing the dwellings. The results presented in this paper will provide a deeper understanding of social housing tenants heating preferences and the data presented could be used in energy models to provide more realistic predictions of the space heating energy demands of the social housing stock. In addition, the analysis could enable social housing providers, the government and technology designers and providers to target energy efficiency measures and social interventions at those dwellings and households where their impact may be most beneficial.

\section{Literature review}

\subsection{Heating setpoint temperatures}

The World Health Organisation (WHO) recommends a comfortable indoor temperature of $21^{\circ} \mathrm{C}$ to prevent potential health effects [28]. Previous studies have reported a range of thermostat setpoint temperatures used in homes using two methods: occupant reported [9], [12], [29]-[32] or estimated from indoor air temperature measurements [9], [11], [26], [33]. A detailed assessment of the methods are provided by Kane et al. [34]. Earlier research has also stated that there is no relationship between the occupant reported and estimated thermostat setting [9, 30]. In reality, the estimated and actual thermostat setpoint temperature may be different for several reasons: an installed TRV may be set to a lower temperature setting than the thermostat, curtailing the maximum temperature reached; or the radiator in a room may be undersized compared to the room heat loss through gaps in the building fabric and window and/or door opening.

Table 1 presents the thermostat setpoint temperatures for UK dwellings with gas central heating reported in previous studies. The standard deviations (SD) of the reported temperatures indicate the variation between homes. The results challenge the underpinning assumptions in building models, such as BREDEM (the Building Research Establishment's Domestic Energy Model). Most domestic building design models incorporate BREDEM's default values for heating setpoint temperatures $\left(21^{\circ} \mathrm{C}\right.$ in living rooms and $18^{\circ} \mathrm{C}$ for the rest of the dwelling) and heating durations (nine hours on weekdays and 16 hours on weekends) [35]. Previous studies have shown that such assumptions misrepresent the 
variability of heating setpoint temperatures and heating durations found in real homes [9], [11], [12], [26], [27], [36]. The heating setpoint temperatures have been identified as the most significant input into building energy models [37]. Multiple factors influence occupants' choice of heating setpoint temperatures and result in significant variation across the housing stock. Despite the increasing amount of work being done in this subject area, there is still not much in the way of an alternative to these default values.

Furthermore, BREDEM-based models assume that dwellings are split into two zones: a living area and the rest of the dwelling. The use of TRVs in homes brings into question this assumption as there is an implication that there is a second level of setpoint temperatures being used in different rooms in an individual dwelling. This is an energy efficiency measure. Thermal upgrades and energy efficiency installations have resulted in lowered amount of energy demand for space heating. However, several studies have highlighted significant differences in energy use in similar buildings and have suggested that occupant behaviour is a strong influence on this [38]-[40]. There is suggestion that the inadequacies of the foundation of the heating values (both setpoint temperatures and heating durations) currently being used in domestic building energy modelling undermines the credibility of recommendations generated in predictive policy making and scenario-planning processes [41]. To ensure that future energy consumption predictions from the housing stock are accurate, a better understanding about occupant's heating preferences throughout their homes is needed. Heating metrics which better define the range and variation in how occupants heat their homes should be developed to increase the knowledge of thermal conditions in dwellings. This will provide a more accurate foundation for energy modelling which will in turn enable a more accurate prediction of energy use across the housing stock.

Table 1 Space heating setpoint temperatures reported in previous studies

\begin{tabular}{|c|c|c|c|}
\hline Study & Study method & $\begin{array}{l}\text { Number of } \\
\text { dwellings }\end{array}$ & $\begin{array}{l}\text { Average heating setpoint } \\
\text { temperature }\left({ }^{\circ} \mathrm{C}\right)(\mathrm{SD})^{\star}\end{array}$ \\
\hline Shipworth et al. [9] & Occupant reported & 164 & $19.0(3.0)$ \\
\hline (UK) & $\begin{array}{l}\text { Estimated from } \\
\text { measurements }\end{array}$ & 195 & $21.1(2.5)$ \\
\hline $\begin{array}{l}\text { Huebner et al. [11] } \\
\text { and [36] }\end{array}$ & $\begin{array}{l}\text { Estimated from } \\
\text { measurements }\end{array}$ & 248 & 20.6 \\
\hline $\begin{array}{l}\text { Jones et al. [12] } \\
\text { (UK) }\end{array}$ & Occupant reported & 111 & $20.9(3.3)$ \\
\hline $\begin{array}{l}\text { Kane et al. (UK) } \\
\text { [26] }\end{array}$ & $\begin{array}{l}\text { Estimated from } \\
\text { measurements }\end{array}$ & 249 & $20.9(3.2)$ \\
\hline $\begin{array}{l}\text { Huebner et al. } \\
\text { (UK) [27] }\end{array}$ & $\begin{array}{l}\text { Estimated from } \\
\text { measurements }\end{array}$ & 275 & $19.7-21.7(2.1-3.1)^{\star \star}$ \\
\hline \multirow[t]{2}{*}{$\begin{array}{l}\text { Kane et al. (UK) } \\
\text { [34] }\end{array}$} & $\begin{array}{l}\text { Estimated from } \\
\text { measurements } \\
\text { (maximum temperature) }\end{array}$ & 20 & 20.2 \\
\hline & $\begin{array}{l}\text { Estimated from } \\
\text { temperature (average } \\
\text { temperature) }\end{array}$ & & 19.4 \\
\hline
\end{tabular}

${ }^{*}$ where the SD is not included, the SD was not reported by the authors of the original study

** Four clusters of typical household temperature profiles were assessed

\subsection{The role of thermostatic radiator valves for energy demand reduction}

TRVs offer a cheap and easy way of providing zoned temperature control within a building. They are designed with settings marked with numbers, often ranging from 0 to 5 . Each position has a corresponding setpoint temperature $\left(0-28^{\circ} \mathrm{C}\right)$. A ( $\left.{ }^{*}\right)$ setting can also be found on TRVs and sets a temperature for frost protection. TRVs sense the air temperature and regulate the flow of hot water through the radiator, allowing for zonal temperature control. TRVs will only allow the flow of hot water to the radiator if the central heating boiler is in operation. They do not control the boiler operation, only the zonal temperature. They consist of two parts: the valve head and the valve body. When the zone 
temperature changes, a capsule in the valve head contracts or expands causing the valve body to open or close and hence controlling the flow of hot water into the radiator. The capsule in the valve therefore responds to fluctuations in indoor temperature allowing the TRV to control the heating demand in the zone. Allowing rooms that are not often occupied to be heated to cooler temperatures (or not heated at all) reduces the internal and external temperature difference and reduces the rate of heat loss and thus heating energy demand.

A few studies have investigated the use of TRVs in homes, Andersen et al. [33] studied 13 dwellings and found differences in TRV setpoint temperatures between dwellings and also between living rooms and bedrooms in individual dwellings. Kane et al. [26] also reported an average difference of $1.1^{\circ} \mathrm{C}$ between mean winter temperatures in living rooms and bedrooms. The average temperature was $18.5^{\circ} \mathrm{C}(\mathrm{SD}=3.0)$ in living rooms and $17.4^{\circ} \mathrm{C}(\mathrm{SD}=2.9)$ in bedrooms. In their study, $68 \%$ of living rooms were warmer than bedrooms $(n=249)$. These findings suggest that occupants regulate the thermal conditions in different rooms within their home at least in part through the use of heating controls such as TRVs.

Beyond the simple TRVs described above, programmable TRVs have recently become available and can be used to set both zonal temperatures and timing schedules to provide heating when needed (e.g. when the zone is occupied). In a study by Beizaee et al. [42], a pair of identical 1930s semi-detached houses were modelled to estimate the potential energy savings from zonal heating controls (simple compared to programmable TRVs) and to assess the mean indoor temperatures during occupied periods. Over the test period, the dwelling with programmable TRVs, where rooms were only heated when they were occupied, had shorter heating periods and used $11.8 \%$ less gas compared to the conventional heating control dwelling (i.e. thermostat, timer and simple TRVs). Furthermore, a $0.6^{\circ} \mathrm{C}$ reduction in mean indoor temperature was observed for the whole house; however, mean temperatures in the rooms during occupied hours were not reduced.

The energy saving potential of zonal heating control in dwellings has also been modelled by Cockroft et al. [43]. In their study, simulations for dwellings with only a whole house thermostat were compared with dwellings with programmable TRVs. Comparing results from the simulations for the non-zoned and zoned conditions, in the zoned conditions, the differences in temperatures between the heating and non-heating periods were larger but as a result energy savings of between $8 \%$ and $37 \%$ were achieved. The study demonstrated that significant energy savings can be achieved by adopting a multi-zonal control strategy where both time and temperature in individual rooms are controlled compared to having a single control strategy for the whole dwelling. In addition, the study showed that there are differences in the potential energy savings according to dwelling and household characteristics. The study was however limited to only two dwelling types (i.e. a semi-detached house and a detached bungalow) and four household types (i.e. young family with two children, four person family with teenagers, elderly couple and young couple) and therefore a deeper understanding of zonal heating control is still needed. The current study provides an assessment of the impact of a wider range of dwelling and household characteristics, including householder motivation, perceptions and behaviour on the use of TRVs to control heating in living rooms and bedrooms.

\section{Current study}

This paper aims to provide an understanding of the use of heating controls (i.e. thermostats and TRVs) in UK social housing according to dwelling (e.g. type, age, number of habitable rooms, etc.), household (e.g. size, composition, health status, etc.) and motivation, behaviour and perception characteristics (e.g. affordability of energy bills, perceived control over energy use, heating related behaviours, etc.). The study will investigate the choice of setpoint temperatures for the whole house (i.e. the thermostat setting), as well as for two zones, the living room and the bedroom (i.e. the TRV settings). The study uses data from a socio-technical household survey which includes self-reported thermostat setting and TRV settings in living rooms and bedrooms and assesses mean temperature values selected by the occupants. This paper responds to a number of gaps identified in the literature. Firstly, the lack of 
studies of the factors influencing the choice of TRV settings in homes, especially for UK social housing. Secondly, the absence of hard data on the setpoint temperatures that should be used in building energy models for zonal heating control. Thirdly, the lack of evidence as to how occupants are using available heating controls.

This paper provides an insight into social housing tenants' use of heating controls and provides zonal setpoint temperature values which could be used to obtain more realistic predictions of the space heating energy demands of the social housing stock. Previous studies on occupant heating behaviour have focussed on owner-occupied and privately rented dwellings [9], [11], [16], [26], [27], [36]. The study presented in this paper targets a better understanding of heating behaviour in social houses. Across the UK, social housing represents $17.4 \%$ of the housing stock and therefore is a significant target for energy efficiency measures. Social housing tenants are often likely to have low or fixed household incomes and as a result are keenly aware of the cost of energy [44] and are also at risk of experiencing fuel poverty [45]. The analysis could enable social housing providers, the government and technology designers and providers to target energy efficiency measures (i.e. thermal upgrades) and social interventions (i.e. behaviour change) at those dwellings and households where their impact may be most beneficial.

\section{Methods}

The data analysed in this paper are derived from a socio-technical household survey and dwelling audits undertaken as part of the European Horizon 2020 research project: Energy Game for Awareness of energy efficiency in social housing communities (EnerGAware) which was conducted in the city of Plymouth, UK [46]. The social housing investigated in this study are managed by the housing association DCH (formerly Devon and Cornwall Housing) who are also a partner of the project. Plymouth was the case study city chosen, as it has one of the largest social housing stocks in the UK, accounting for $20.1 \%$ of the city's housing [47]. In Plymouth, the allocation system for social housing is in accordance with the guidance specified in Part 6 of the Housing Act (Allocation of Housing Accommodation [48]). Priority is always given to people considered as vulnerable (e.g. the homeless or threatened with homelessness, people living in unsanitary, overcrowded housing, having medical or welfare needs). The average gross weekly income of households living in social housing is $£ 317,42.8 \%$ less than private renters' weekly income. A quarter of households living in the social housing have done so for between 10 and 20 years [49]. A comparison of current study's social housing stock sample with the social housing stock at a national scale is presented in Table 3 (Section 4.2).

A detailed description of the socio-technical household survey and building audits are provided in Jones et al. [12]. In summary, the socio-technical survey was administered to 2,772 social houses (social rented and shared ownership) in Plymouth, which represents $12.6 \%$ of the city's social housing stock [47]. The households receiving the survey represented all of the social housing in Plymouth managed by housing association $\mathrm{DCH}$. The survey was occupant self-reported through either a paper based postal questionnaire or an online questionnaire administered through the Internet survey software, SurveyMonkey and was conducted in May 2015. The survey contained 68 standardised closed questions. Within five weeks of the survey being sent out, 537 responses had been received (504 paperbased and 33 online), giving an overall response rate of $19.4 \%$. The socio-technical household survey provided information for this paper about the household characteristics (e.g. household size and composition, highest qualification of HRP (HRP) ${ }^{2}$, health of HRP and disabled household members), motivation, behaviour and perception characteristics (e.g. affordability of energy bills, worry about energy bills, understanding, perceived control of energy use at home, perceived ability to save energy at home, heating related behaviours and dwelling occupancy pattern), as well as occupant reported winter living room and bedroom TRV settings and the whole house thermostat setpoint temperatures.

The building audit data were obtained from the social housing association's asset management and building stock condition database. The data are collected and managed by an in-house team of professional building surveyors. Building audits have been conducted between 2009 and 2017 and a continuous process of carrying out the audits is maintained to ensure that property data is correct and

\footnotetext{
${ }^{2}$ The Household Representative Person (HRP) is the individual that is taken to represent that household. In this study it describes the person that completed the survey.
} 
up to date (i.e. once a change to a dwelling's structure or services occurs, a new building audit is undertaken). The dataset provides a comprehensive overview of the key structural elements and services in each home and also contains the dataset for the RdSAP energy rating methodology which enables a Standard Assessment Procedure (SAP) rating to be calculated for each dwelling [50]. The social housing association's asset management and building stock condition database provided data for this paper about the dwelling characteristics (e.g. dwelling type and age, number of floors and habitable rooms, wall construction and insulation, roof construction and insulation thickness, heating system and SAP rating). This data represented the state of the dwellings at the time the socio-technical survey was conducted.

\subsection{Data processing}

Each setting on a TRV, often ranging from 0 to 5 has a corresponding setpoint temperature $\left(0-28^{\circ} \mathrm{C}\right)$, which represents the maximum temperature at which the radiator in an individual room is turned off. The occupant reported living room and bedroom TRV settings were converted to their corresponding setpoint temperatures by referring to the manufacturer's specifications. The setting temperatures varies depending on the manufacturer and also the product model. They typically range from $0^{\circ} \mathrm{C}$ to $28^{\circ} \mathrm{C}$ with variations in the temperatures for corresponding settings occurring due to some TRVs ranging from 0 to 5 and others 0 to 6 . The frost protection setting $\left(^{*}\right)$ operates at a mean temperature typically below $6.9^{\circ} \mathrm{C}$. Table 2 presents the TRV setting and the mean corresponding setpoint temperatures used in the current study based on the manufacturers' specifications. Where the TRVs had settings up to 6 , the maximum temperature for each setting is lower compared to TRVs with settings up to 5 only.

From all the households that reported TRV settings, the TRVs were on in all the living rooms with a setting between 2 and 6 . In the bedrooms, the TRVs were off (i.e. set to 0 ) in 29 dwellings and set to the frost protection setting $\left(^{*}\right)$ in one dwelling. Where TRVs were on in the bedrooms, the settings ranged from 1 to 6 . In both rooms, the most commonly used TRV setting was 3 which corresponds to a setpoint temperature of $20^{\circ} \mathrm{C}$. From the whole sample, 95 dwellings had the same TRV setting in the living room and bedroom. For the dwellings with different living room and bedroom TRV settings the average setting in the living room was 4 and 3 in the bedroom, indicating that in some households, there is a preference for cooler conditions in bedrooms. A comparison of households which reported a whole house thermostat setting, with households which reported TRV settings is presented in this paper. Out of the 187 households that provided living room TRV settings, 144 also provided a whole house thermostat setting and of the 189 households that provided bedroom TRV settings, 143 provided a thermostat setpoint temperature.

Table 2 TRV settings and corresponding mean setpoint temperatures

\begin{tabular}{cc}
\hline TRV setting & Mean setpoint temperature $\left({ }^{\circ} \mathbf{C}\right)$ \\
\hline${ }^{\text {(frost protection) }}$ & 6.9 \\
0 & 0 \\
1 & 11.8 \\
2 & 15.9 \\
2.5 & 18.0 \\
3 & 20.0 \\
3.5 & 21.9 \\
4 & 23.9 \\
4.5 & 25.8 \\
5 & 27.8 \\
6 & 26.0
\end{tabular}

\subsection{Sample characteristics}

This paper examines the TRV settings of a sub-sample of the 537 households, those which heated their homes with a gas-fired boiler and had TRVs for controlling the temperatures in individual rooms as well as a thermostat for defining the heating setpoint temperature for the whole house. The data regarding the presence of heating controls in the dwellings were obtained from the housing association's asset management and building stock condition database. Gas-fired central heating systems are the focus of the current paper because they are installed in $91 \%$ of the UK housing stock [3]. 
A comparison of the social housing subsamples used in this paper with the composition of the social housing stock at the national scale as reported in the 2013-14 English Housing Survey [51] is provided in Table 3. Of the 537 households responding to the survey, 187 provided a TRV setting for the radiator in the living room and 189 provided a TRV setting for the radiator in the bedroom. Of the 189 households that provided a bedroom TRV setting, 29 reported a setting of 0 implying that the radiator in the bedroom was turned off.

It can be seen that the study subsamples under-represented semi-detached dwellings but overrepresented terraced dwellings. There was also an over-representation of smaller household sizes (i.e. one and two occupants) and a subsequent under-representation of households with three or more occupants. The percentages of households with retired HRPs are higher in the study subsamples compared to that in the EHS. Households that were comprised of couples only were over-represented and households comprised of couples with dependent children and other multi-person households (e.g. students, three or more adults) were under-represented.

Table 3 Composition of the study subsamples compared to the 2013-14 English Housing Survey (EHS)

\begin{tabular}{|c|c|c|c|}
\hline Characteristics & $\begin{array}{l}\text { Living room TRV } \\
\text { setpoint } \\
\text { temperature } \\
\text { sample }(\%) n= \\
187\end{array}$ & $\begin{array}{l}\text { Bedroom TRV } \\
\text { setpoint } \\
\text { temperature } \\
\text { sample }(\%) n= \\
159\end{array}$ & $\begin{array}{l}\text { EHS, 2013-14 } \\
(\%) \\
n=3,449 \\
\text { (social housing } \\
\text { only) }\end{array}$ \\
\hline \multicolumn{4}{|l|}{ Dwelling type } \\
\hline Detached & 0.0 & 0.0 & 1.2 \\
\hline Semi-detached & 9.1 & 10.7 & 21.9 \\
\hline Terraced (end and mid) & 48.7 & 48.8 & 32.3 \\
\hline Flat or maisonette & 42.2 & 40.9 & 44.3 \\
\hline \multicolumn{4}{|l|}{ Household size } \\
\hline 1 & 51.9 & 50.9 & 40.9 \\
\hline 2 & 30.5 & 30.2 & 26.2 \\
\hline 3 & 8.6 & 7.5 & 14.9 \\
\hline 4 & 3.7 & 4.4 & 10.4 \\
\hline $5+$ & 5.3 & 6.9 & 7.6 \\
\hline \multicolumn{4}{|l|}{ Employment status of HRP } \\
\hline Employed & 34.2 & 31.7 & 36.7 \\
\hline Unemployed & 6.6 & 6.3 & 8.6 \\
\hline Retired & 44.7 & 44.4 & 29.6 \\
\hline Student & 2.6 & 1.6 & 1.3 \\
\hline Other & 11.8 & 15.9 & 23.8 \\
\hline \multicolumn{4}{|l|}{ Household composition } \\
\hline One person & 41.8 & 44.4 & 40.9 \\
\hline Couple, no dependent children & 28.4 & 25.9 & 17.5 \\
\hline Couple with dependent child(ren) & 6.0 & 9.3 & 14.1 \\
\hline Lone parent with dependent child(ren) & 19.4 & 18.5 & 17.3 \\
\hline Other multi-person household & 4.5 & 1.9 & 10.3 \\
\hline
\end{tabular}

\section{Data analysis}

This paper provides an analysis of the variations in mean winter TRV setpoint temperatures in living rooms and bedrooms used in UK social housing according to dwelling, household, and motivation, behaviour and perception characteristics. The analysis of TRV setpoint temperatures aims to highlight the role of TRVs in social housing tenants space heating behaviours: variations in zonal heating control behaviour and differences between the whole house thermostat setting and the TRV settings used in individual zones.

For the analysis, the frost protection setting was excluded as it was deemed to be an outlier. All ' 0 ' settings were also excluded from the analysis as they indicate that the radiators were not in use. These 
were only reported for bedroom TRVs. For the remainder of the dataset (187 for living rooms and 159 for bedrooms), statistical tests were used to assess the relationship between the dependent variable (the TRV setpoint temperature) and a set of independent variables (dwelling, household, motivation, behaviour and perception characteristics). The analysis was conducted using the IBM SPSS Statistics 24 package. When there are two groups, t-tests for independent samples are used and if there are three or more groups, analysis of variance is used. The difference between the mean temperatures in the groups are said to be statistically significant when the variance between the data points within each group is small compared to the difference in the means of the groups. As not all households answered all the questions in the survey, the sample sizes for the groups are not equal. Hence for the statistical tests, equal variances were not assumed. Results that were statistically significant at the $5 \%(p<0.05)$, $1 \%(p<0.01)$ and $0.1 \%(p<0.001)$ levels were identified.

\section{Results}

\subsection{Mean TRV setpoint temperatures in living rooms and bedrooms}

Table 4 shows the variations in mean reported TRV setpoint temperatures in relation to zone (living room and bedroom), dwelling, household and motivation, behaviour and perception characteristics.

The mean reported TRV setpoint temperature was $23.4^{\circ} \mathrm{C}$ in the living room and $21.9^{\circ} \mathrm{C}$ in the bedroom and the difference in the mean temperatures was significant $(p<0.001)$. This implies that there is a preference for cooler conditions in bedrooms than the living rooms and shows that social housing tenants use their TRVs to zonally control temperatures in different rooms.

Significant differences in the TRV settings selected by households were found between living rooms in end terrace and mid terrace dwellings $(p<0.05)$. Respondents in end terrace dwellings reported using higher TRV settings $(M=24.5, S D=3.7)$ than those in mid terrace dwellings $(M=22.3, S D=3.2)$. No statistically significant differences in bedroom TRV settings were observed according to dwelling type. For both living rooms and bedrooms, the differences in TRV settings for all the other assessed dwelling characteristics were not significant.

Regarding number of floors in the dwellings, differences in TRV settings were found between dwellings with 3 floors and dwellings on only 1 floor. In the living rooms, the mean TRV setpoint temperature was $24.6^{\circ} \mathrm{C}(\mathrm{SD}=2.8)$ in dwellings with 3 floors and $23.6^{\circ} \mathrm{C}(\mathrm{SD}=3.4)$ in dwellings on 1 floor. In the bedrooms, the mean TRV setpoint temperature was $22.8^{\circ} \mathrm{C}(\mathrm{SD}=5.0)$ in dwellings with 3 floor and $21.9^{\circ} \mathrm{C}(S D=4.0)$ in dwellings on 1 floor. These differences were also not statistically significant.

However, there were other interesting observations. In the living rooms, the least energy efficient dwellings according to the SAP rating $(E-G)$ had higher TRV settings $(M=24.8, S D=2.4)$ than the most efficient dwellings $(B)(M=22.5, S D=4.0)$. Overall, living room TRV settings increased with decreasing dwelling efficiency. In the bedrooms, the analysis found that dwellings that have at least $250 \mathrm{~mm}$ thickness of roof insulation had lower TRV settings $(M=19.9, S D=4.4)$ than dwellings with up to $200 \mathrm{~mm}$. Furthermore, the lower $95 \% \mathrm{Cl}$ indicated that $5 \%$ of dwellings with $250 \mathrm{~mm}$ of roof insulation used bedroom TRV settings of $18^{\circ} \mathrm{C}$ or cooler, whereas dwellings with up to $100 \mathrm{~mm}$ had an upper $95 \%$ $\mathrm{Cl}$ of $25^{\circ} \mathrm{C}$.

In relation to household characteristics, social housing residents that had been living in their dwellings for at least 20 years reported lower mean living room and bedroom TRV settings than those residing for less than 20 years. In the living rooms, the difference was significant for those with a tenancy duration of at least 20 years $(M=21.8, S D=2.9)$ compared to those with a $6-10$ year tenancy duration $(M=$ $24.2,3.4 ; p=0.003)$ and less than 3 year tenancy duration $(\mathrm{M}=23.6,3.7 ; p=0.019)$. Mean bedroom TRV settings in households with at least 20 years tenancy were also lower $(M=19.0, S D=4.1)$, with the lower $95 \% \mathrm{Cl}$ indicating that $5 \%$ of these households used TRV settings of $17^{\circ} \mathrm{C}$ or cooler. This TRV setting was significantly different from households with an up to three year tenancy duration ( $\mathrm{M}=$ 22.6, $\mathrm{SD}=4.2 ; p=0.003$ ). 
In both living rooms and bedrooms, the analysis showed that TRV settings were highest in households with at least four members (living room household size $4: M=23.4, S D=4.0$ and $5+: M=24.1, S D=$ 3.7; bedroom, household size $4: M=22.8, S D=3.7$ and $5+: M=22.3, S D=3.8$ ). Although generally increased household size seemed to be associated with higher TRV settings, for households with 4 or members, the lower $95 \% \mathrm{Cl}$ indicated that $5 \%$ of the households used TRV settings of $19.6^{\circ} \mathrm{C}$ or lower in living rooms and $19.4^{\circ} \mathrm{C}$ or lower in bedrooms.

Households where couples lived with dependent children were found to have the highest TRV settings in both living rooms and bedrooms (living room: $M=22.3, S D=5.3$; bedroom: $M=25.4, S D=3.7$ ). The average TRV settings reported in lone parent households were lowest in both rooms (living room: $M=$ $22.2, \mathrm{SD}=3.1$; bedroom: $\mathrm{M}=20.7, \mathrm{SD}=4.3$ ). The coldest $5 \%$ of living rooms occupied by lone parent families reported a TRV setting of $19.4^{\circ} \mathrm{C}$ and the coldest $5 \%$ of bedrooms occupied by lone parent families reported a TRV setting of $15.4^{\circ} \mathrm{C}$. Both temperatures are below the $21^{\circ} \mathrm{C}$ recommended by the WHO.

Households in receipt of welfare benefits reported higher TRV settings in both living rooms ( $M=24.1$, $\mathrm{SD}=3.2)$ and bedrooms $(\mathrm{M}=22.7, \mathrm{SD}=3.9)$ compared to those not in receipt of benefits. In the living room, the difference in means between the two groups was $1.1^{\circ} \mathrm{C}$ and this was statistically significant $(p=0.049)$.

There were no statistical differences in the mean TRV settings in dwellings where the HRP considered their general health as very good, good, fair, bad or very bad. The main concern is that for households where the HRP reported being in bad general health, the coldest $5 \%$ of households reported using TRV setpoint temperatures up to $18.8^{\circ} \mathrm{C}$.

Regarding overall satisfaction with life, bedroom TRV settings in households where the HRP reported dissatisfaction were higher $(M=24.3, S D=4.5)$ than those who reported being neither dissatisfied nor satisfied or satisfied. The difference in the mean bedroom TRV settings was statistically significant between the dissatisfied group and the satisfied group $(p=0.03)$.

Regarding occupancy patterns, households that are always occupied reported slightly higher TRV settings. The mean difference was $0.5^{\circ} \mathrm{C}$ in living rooms and $0.3^{\circ} \mathrm{C}$ in bedrooms. These differences were also reported in the living rooms during weekday and weekend daytimes and evenings. For bedrooms, the TRV settings were warmer in households that were not occupied during weekday evenings and weekend daytimes and evenings.

Regarding motivation and perception characteristics, households which strongly agreed that they worry about their energy bills were also found to select the highest TRV settings in the living room ( $M=24.1$, $S D=3.5)$ and those who strongly disagreed had the lowest settings $(M=22.7, S D=3.8)$.

Households who strongly agreed that they did not understand how their home used energy had higher living room TRV settings $(M=24.6, S D=3.6)$ than those who strongly disagreed $(M=22.4, S D=3.7)$.

Households that again strongly agreed that they have control over how much energy is used in their homes selected lower TRV settings in their living rooms $(M=22.1, S D=3.0)$ and bedrooms $(M=20.7$, $S D=3.1$ ) than those who strongly disagreed (living room: $M=25.1, S D=3.3$; bedroom: $M=23.6, S D$ $=4.8$ ).

Households that strongly agreed that they are not able to save any more energy selected higher mean TRV settings (living rooms: $M=23.7, S D=3.1$; bedrooms: $M=22.4, S D=3.8$ ) than those who strongly disagreed (living rooms: $\mathrm{M}=22.0, \mathrm{SD}=3.6$; bedrooms: $21.4, \mathrm{SD}=3.1$ ).

Regarding heating behaviour characteristics, the analysis showed that households that said that they adjusted the setting on their radiators also in general reported selecting lower TRV settings. This was observed in the living rooms and the bedrooms. In the living rooms, the difference between households that never adjusted their TRV setting $(M=25.3, S D=3.0)$ was statistically different $(p<0.001)$ from the households that adjusted their TRV setting often ( $M=22.4$, SD = 3.2). In the bedrooms, the differences were significant between households that never adjusted the setting ( $M=25.1, S D=3.2)$ 
and those who adjusted the setting always $(M=21.9, S D=4.0 ; p=0.002)$, often $(M=20.1, S D=3.7$; $p<0.001)$ and sometimes $(\mathrm{M}=21.4, \mathrm{SD}=4.7 ; p=0.002)$.

There was no clear relationship between whether occupants changed the temperature on their whole house thermostat, and the living room TRV setting, but in the bedrooms, households that reported never changing the temperature on their whole house thermostat also reported higher TRV settings $(M=24.6$, $\mathrm{SD}=3.4)$ compared to those who said they always change the temperature on their thermostat $(\mathrm{M}=$ $21.9, \mathrm{SD}=4.0)$. 
Table 4 Occupant reported mean TRV setpoint temperatures in living rooms and bedrooms and dwelling, household, motivation, behaviour and perception characteristics

\begin{tabular}{|c|c|c|c|c|c|c|}
\hline \multirow[b]{2}{*}{ Characteristics } & \multicolumn{3}{|c|}{ Reported winter heating TRV setting in living rooms $\left({ }^{\circ} \mathrm{C}\right)$} & \multicolumn{3}{|c|}{ Reported winter heating TRV setting in bedrooms $\left({ }^{\circ} \mathrm{C}\right)$} \\
\hline & $\mathrm{n}$ & Mean $(95 \% \mathrm{Cl})$ & SD & $\mathrm{n}$ & Mean $(95 \% \mathrm{Cl})$ & SD \\
\hline All dwellings & 187 & $23.4(22.9,23.9)^{* *}$ & 3.5 & 159 & $21.9(21.2,22.6)^{\star \star}$ & 4.3 \\
\hline \multicolumn{7}{|l|}{ Dwelling characteristics } \\
\hline \multicolumn{7}{|l|}{ Dwelling type } \\
\hline End terrace house & 30 & $24.5(23.1,25.9)^{*}$ & 3.7 & 29 & $21.8(19.9,23.7)$ & 5.0 \\
\hline Mid terrace house & 61 & $22.3(21.5,23.1)^{\star}$ & 3.2 & 48 & $21.1(19.9,22.2)$ & 4.1 \\
\hline Semi-detached house & 11 & $24.1(22.2,26.1)$ & 2.9 & 13 & $22.4(19.4,25.4)$ & 4.9 \\
\hline Semi-detached bungalow & 6 & $24.6(21.5,27.6)$ & 2.9 & 4 & $19.0(15.7,22.2)$ & 2.1 \\
\hline Flat/Maisonette & 79 & $23.7(22.9,24.5)$ & 3.5 & 65 & $22.7(21.7,23.6)$ & 4.0 \\
\hline \multicolumn{7}{|l|}{ Period dwelling was built } \\
\hline Pre 1900 & 9 & $22.8(19.5,26.1)$ & 4.3 & 9 & $21.9(18.0,25.8)$ & 5.0 \\
\hline $1900-1949$ & 9 & $23.2(20.9,25.6)$ & 3.1 & 9 & $19.0(15.0,23.0)$ & 5.2 \\
\hline $1950-1975$ & 20 & $24.0,(22.3,25.7)$ & 3.6 & 17 & $21.2(19.0,23.4)$ & 4.3 \\
\hline $1976-1982$ & 26 & $23.8(22.6,25.1)$ & 3.1 & 19 & $23.3(21.4,25.2)$ & 3.9 \\
\hline $1983-1990$ & 25 & $24.8(23.5,26.1)$ & 3.1 & 15 & $21.4(18.9,23.9)$ & 4.5 \\
\hline $1991-1995$ & 28 & $23.7(22.4,25.0)$ & 3.4 & 28 & $22.9(21.3,24.5)$ & 4.1 \\
\hline $1996-2006$ & 22 & $22.4(20.9,23.9)$ & 3.5 & 20 & $21.5(19.8,23.3)$ & 3.8 \\
\hline Post 2007 & 48 & $22.7(21.6,23.8)$ & 3.7 & 42 & $21.8(20.5,23.1)$ & 4.2 \\
\hline \multicolumn{7}{|l|}{ Number of floors } \\
\hline 1 & 101 & $23.6(22.9,24.3)$ & 3.4 & 84 & $21.9(21.1,22.8)$ & 4.0 \\
\hline 2 & 75 & $23.1(22.2,23.9)$ & 3.6 & 66 & $21.7(20.6,22.8)$ & 4.5 \\
\hline 3 & 11 & $24.6(22.7,26.5)$ & 2.8 & 9 & $22.8(19.0,26.6)$ & 5.0 \\
\hline \multicolumn{7}{|l|}{ Number of habitable rooms } \\
\hline 2 & 33 & $24.0(22.8,25.1)$ & 3.2 & 26 & $22.3(20.7,23.9)$ & 4.0 \\
\hline 3 & 68 & $23.2(22.3,24.1)$ & 3.6 & 57 & $21.4(20.3,22.6)$ & 4.2 \\
\hline 4 & 57 & $23.6(22.8,24.5)$ & 3.3 & 51 & $22.2(21.0,23.4)$ & 4.3 \\
\hline $5-6$ & 7 & $23.9(21.2,26.7)$ & 3.0 & 6 & $20.6(15.0,26.2)$ & 5.3 \\
\hline \multicolumn{7}{|l|}{ Wall construction type } \\
\hline Cavity & 88 & $23.2(22.5,23.9)$ & 3.3 & 71 & $21.5(20.5,22.7)$ & 4.0 \\
\hline Solid wall & 52 & $24.3(23.3,25.3)$ & 3.6 & 47 & $22.5(21.1,23.9)$ & 4.6 \\
\hline Timber frame & 17 & $23.6(21.9,25.3)$ & 3.3 & 15 & $22.2(19.9,24.6)$ & 4.3 \\
\hline \multicolumn{7}{|l|}{ Wall insulation type } \\
\hline Cavity/solid wall insulation & 74 & $23.5(22.8,24.3)$ & 3.2 & 58 & $21.5(20.4,22.7)$ & 4.4 \\
\hline As-built & 83 & $23.6(22.8,24.4)$ & 3.6 & 75 & $22.2(21.2,23.2)$ & 4.2 \\
\hline \multicolumn{7}{|l|}{ Roof construction type } \\
\hline Pitched with loft access & 115 & $23.2(22.6,23.9)$ & 3.3 & 98 & $21.4(20.5,22.2)$ & 4.2 \\
\hline Flat & 10 & $24.3(21.9,26.7)$ & 3.3 & 7 & $24.2(19.9,28.5)$ & 4.6 \\
\hline Other dwelling above & 27 & $24.5(22.9,26.1)$ & 4.1 & 25 & $23.1(21.3,24.9)$ & 4.3 \\
\hline \multicolumn{7}{|l|}{ Roof insulation thickness } \\
\hline $50-100 \mathrm{~mm}$ & 20 & $24.3(22.7,25.9)$ & 3.4 & 17 & $22.8(20.3,25.3)$ & 4.9 \\
\hline $150 \mathrm{~mm}$ & 38 & $24.0(22.9,25.1)$ & 3.2 & 35 & $21.9(20.5,23.2)$ & 4.0 \\
\hline $200 \mathrm{~mm}$ & 17 & $22.3(20.4,24.2)$ & 3.6 & 14 & $21.9(19.7,24.2)$ & 4.0 \\
\hline $250 \mathrm{~mm}+$ & 30 & $23.1(21.8,24.5)$ & 3.6 & 22 & $19.9(18.0,21.9)$ & 4.4 \\
\hline $\begin{array}{l}\text { SAP rating } \\
\mathrm{B}(85-99)\end{array}$ & २? & $22.5(20.7 .24 .2)$ & 4.0 & 19 & $21.9(19.7 .24 .1))$ & 4.5 \\
\hline
\end{tabular}




\begin{tabular}{|c|c|c|c|c|c|c|}
\hline \multirow[b]{2}{*}{ Characteristics } & \multicolumn{3}{|c|}{ Reported winter heating TRV setting in living rooms $\left({ }^{\circ} \mathrm{C}\right)$} & \multicolumn{3}{|c|}{ Reported winter heating TRV setting in bedrooms $\left({ }^{\circ} \mathrm{C}\right)$} \\
\hline & $\mathrm{n}$ & Mean $(95 \% \mathrm{Cl})$ & SD & $\mathrm{n}$ & Mean $(95 \% \mathrm{Cl})$ & SD \\
\hline $\mathrm{C}(70-84)$ & 67 & $23.0(22.2,23.9)$ & 3.5 & 53 & $22.4(21.4,23.5)$ & 3.8 \\
\hline D (55-69) & 87 & $23.8(23.0,24.5)$ & 3.4 & 76 & $21.6(20.6,22.6)$ & 4.5 \\
\hline$E-G(1-54)$ & 11 & $24.8(23.2,26.4)$ & 2.4 & 11 & $21.4(18.4,24.3)$ & 3.8 \\
\hline \multicolumn{7}{|l|}{ Heating system type } \\
\hline Combi & 66 & $24.2(23.3,25.0)$ & 3.3 & 58 & $22.2(21.0,23.3)$ & 4.6 \\
\hline Condensing combi & 89 & $23.1(22.4,23.8)$ & 3.4 & 74 & $21.9(21.0,22.7)$ & 3.8 \\
\hline \multicolumn{7}{|l|}{ Household characteristics } \\
\hline \multicolumn{7}{|l|}{ Duration of tenancy } \\
\hline$<3$ years & 54 & $23.6(22.6,24.6)^{\star}$ & 3.7 & 52 & $22.6(21.4,23.7)^{\star *}$ & 4.2 \\
\hline $3-5$ years & 21 & $23.4(21.9,25.0)$ & 3.4 & 18 & $22.5(20.2,24.7)$ & 4.6 \\
\hline $6-10$ years & 38 & $24.2(23.1,25.3)^{* *}$ & 3.4 & 32 & $22.4(20.9,23.9)$ & 4.1 \\
\hline $11-20$ years & 48 & $23.5(22.5,24.5)$ & 3.4 & 38 & $21.7(20.4,23.0)$ & 4.0 \\
\hline $20+$ years & 26 & $21.8(20.6,22.9)^{\star}$ & 2.9 & 19 & $19.0(17.0,20.9)$ & 4.1 \\
\hline $\begin{array}{l}\text { Age of } H R P \\
18-29\end{array}$ & 28 & $23.5(22.0,25.1)$ & 4.0 & 26 & $23.1(21.3,25.0)$ & 4.6 \\
\hline $30-39$ & 18 & $23.8(22.1,25.5)$ & 3.4 & 15 & $22.6(20.0,25.1)$ & 4.6 \\
\hline $40-49$ & 20 & $23.1(21.5,24.7)$ & 3.4 & 17 & $22.1(20.2,24.0)$ & 3.7 \\
\hline $50-59$ & 41 & $23.2(22.1,24.4)$ & 3.6 & 33 & $21.1(19.6,22.8)$ & 4.6 \\
\hline $60-69$ & 33 & $23.1(21.9,24.2)$ & 3.2 & 26 & $20.8(19.3,22.3)$ & 3.8 \\
\hline $70-79$ & 29 & $23.8(22.6,25.1)$ & 3.4 & 28 & $21.8(20.3,23.2)$ & 3.7 \\
\hline $80_{+}$ & 18 & $23.7(22.0,25.4)$ & 3.4 & 14 & $22.8(20.0,25.5)$ & 4.8 \\
\hline \multicolumn{7}{|l|}{ Household size } \\
\hline 1 & 97 & $23.2(22.6,23.9)$ & 3.4 & 81 & $21.6(20.7,22.5)$ & 4.1 \\
\hline 2 & 57 & $23.8(22.8,24.7)$ & 3.6 & 48 & $22.2(20.8,23.6)$ & 4.9 \\
\hline 3 & 16 & $23.1(21.2,24.9)$ & 3.4 & 12 & $21.9(19.4,24.4)$ & 3.9 \\
\hline 4 & 7 & $23.4(19.6,27.1)$ & 4.0 & 7 & $22.8(19.4,26.2)$ & 3.7 \\
\hline \multicolumn{7}{|l|}{ Household composition } \\
\hline One person & 97 & $23.2(22.6,23.9)$ & 3.4 & 81 & $21.6(20.7,22.5)$ & 4.1 \\
\hline Couple, no dependent children & 55 & $23.4(22.4,24.3)$ & 3.6 & 44 & $21.9(20.4,23.3)$ & 4.7 \\
\hline Couple with dependent child(ren) & 4 & $25.4(19.5,31.3)$ & 3.7 & 5 & $22.3(15.7,28.9)$ & 5.3 \\
\hline Lone parent with dependent child(ren) & 7 & $22.2(19.4,25.1)$ & 3.1 & 5 & $20.7(15.4,26.1)$ & 4.3 \\
\hline Other multiple person household & 1 & 26.0 & & & & \\
\hline \multicolumn{7}{|l|}{ Highest qualification of HRP } \\
\hline O'Level, GCSE, NVQ Level 2 or equivalent & 40 & $23.6(22.6,24.7)$ & 3.3 & 39 & $21.0(19.7,22.4)$ & 4.2 \\
\hline A'Level, NVQ Level 3 or equivalent & 35 & $24.6(23.4,25.8)$ & 3.4 & 33 & $22.8(21.2,24.4)$ & 4.5 \\
\hline Degree level or above & 24 & $22.5(20.6,24.4)$ & 4.4 & 20 & $22.2(20.0,24.4)$ & 4.8 \\
\hline Another kind of qualification & 16 & $24.1(22.1,26.2)$ & 3.8 & 14 & $23.6(21.1,26.2)$ & 4.4 \\
\hline No qualification & 35 & $22.9(21.8,24.3)$ & 3.3 & 27 & $21.6(20.0,23.3)$ & 4.2 \\
\hline \multicolumn{7}{|l|}{ Employment structure } \\
\hline Employed & 26 & $23.8(22.4,25.1)$ & 3.3 & 20 & $21.6(19.2,24.0)$ & 5.1 \\
\hline Unemployed & 5 & $21.5(15.9,27.1)$ & 4.5 & 4 & $20.9(13.0,28.8)$ & 4.9 \\
\hline Retired & 34 & $23.2(21.9,24.4)$ & 3.5 & 28 & $21.7(19.9,23.5)$ & 4.6 \\
\hline Student & 2 & $26.9(15.5,38.3)$ & 1.2 & 1 & $23.7(20.6,26.9)$ & 4.4 \\
\hline \multicolumn{7}{|l|}{ Household in receipt of welfare benefits } \\
\hline Yes & 76 & $24.1(23.4,24.9)^{*}$ & 3.2 & 64 & $22.7(21.7,23.7)$ & 3.9 \\
\hline
\end{tabular}




\begin{tabular}{|c|c|c|c|c|c|c|}
\hline \multirow[b]{2}{*}{ Characteristics } & \multicolumn{3}{|c|}{ Reported winter heating TRV setting in living rooms $\left({ }^{\circ} \mathrm{C}\right)$} & \multicolumn{3}{|c|}{ Reported winter heating TRV setting in bedrooms $\left({ }^{\circ} \mathrm{C}\right)$} \\
\hline & $\mathrm{n}$ & Mean $(95 \% \mathrm{Cl})$ & SD & $\mathrm{n}$ & Mean $(95 \% \mathrm{Cl})$ & SD \\
\hline No & 92 & $23.0(22.3,23.8)^{*}$ & 3.7 & 84 & $21.5(20.5,22.5)$ & 4.6 \\
\hline \multicolumn{7}{|l|}{ Health of HRP } \\
\hline Very good & 34 & $22.9(21.5,24.3)$ & 3.9 & 34 & $21.9(20.5,23.3)$ & 4.0 \\
\hline Good & 50 & $23.3(22.3,24.3)$ & 3.6 & 43 & $21.5(20.1,22.8)$ & 4.2 \\
\hline Fair & 48 & $24.1(23.1,25.0)$ & 3.2 & 39 & $22.9(21.5,24.4)$ & 4.5 \\
\hline Bad & 25 & $23.8(22.5,25.1)$ & 3.2 & 23 & $20.7(18.8,22.6)$ & 4.5 \\
\hline Very bad & 19 & $23.2(21.5,24.9)$ & 3.6 & 13 & $23.1(20.7,25.6)$ & 4.1 \\
\hline \multicolumn{7}{|l|}{ Number of GP visits in a year } \\
\hline $0-1$ & 41 & $23.1(21.9,24.4)$ & 4.0 & 39 & $22.5(21.3,23.8)$ & 3.9 \\
\hline $2-4$ & 43 & $24.0(23.0,25.0)$ & 3.2 & 38 & $22.3(20.7,23.8)$ & 4.6 \\
\hline $5-6$ & 17 & $23.5(21.8,25.2)$ & 3.3 & 14 & $22.1(19.2,24.9)$ & 5.0 \\
\hline $7-12$ & 19 & $24.0(22.1,25.9)$ & 4.0 & 15 & $21.1(18.5,23.7)$ & 4.7 \\
\hline $12+$ & 11 & $23.2(20.9,25.4)$ & 3.3 & 9 & $23.7(21.8,25.6)$ & 2.5 \\
\hline \multicolumn{7}{|l|}{ Household with disabled members } \\
\hline Yes & 79 & $23.4(22.7,24.2)$ & 3.4 & 68 & $21.7(20.7,22.9)$ & 4.5 \\
\hline No & 108 & $23.4(22.8,24.1)$ & 3.6 & 91 & $22.0(21.1,22.8)$ & 4.1 \\
\hline \multicolumn{7}{|l|}{ Satisfaction with life } \\
\hline 0-3 (Dissatisfied) & 25 & $23.3(21.7,24.8)$ & 3.7 & 16 & $24.3(21.9,26.6)^{*}$ & 4.5 \\
\hline 4-6 (Neither dissatisfied nor satisfied) & 64 & $23.9(23.1,24.7)$ & 3.3 & 62 & $21.9(20.8,23.0)$ & 4.2 \\
\hline 7-10 (Satisfied) & 93 & $23.2(22.5,23.9)$ & 3.5 & 78 & $21.4(20.5,22.4)^{*}$ & 4.2 \\
\hline \multicolumn{7}{|c|}{ Household occupancy patterns during heating season } \\
\hline Always occupied & 64 & $23.7(22.9,24.5)$ & 3.2 & 48 & $22.1(20.9,23.3)$ & 4.2 \\
\hline Partially occupied & 122 & $23.2(22.6,23.9)$ & 3.6 & 111 & $21.8(21.0,22.6)$ & 4.3 \\
\hline Occupied during weekday daytimes & 52 & $23.8(22.9,24.6)$ & 3.2 & 49 & $22.1(21.0,23.3)$ & 4.1 \\
\hline Unoccupied during weekday daytimes & 135 & $23.3(22.7,23.9)$ & 3.6 & 110 & $21.8(21.0,22.6)$ & 4.4 \\
\hline Occupied during weekday evenings & 75 & $23.6(22.8,24,4)$ & 3.3 & 71 & $21.8(20.5,23.1)$ & 4.3 \\
\hline Unoccupied during weekday evenings & 111 & $23.3(22.6,24.0)$ & 3.6 & 88 & $22.0(21.1,22.9)$ & 4.3 \\
\hline Occupied during weekend daytimes & 48 & $23.5(22.5,24.5)$ & 3.4 & 44 & $21.7(20.5,23.1)$ & 4.3 \\
\hline Unoccupied during weekend evenings & 138 & $23.4(22.8,24.0)$ & 3.5 & 115 & $21.9(21.1,22.7)$ & 4.3 \\
\hline Occupied during weekend evenings & 69 & $23.7(22.9,24.4)$ & 3.1 & 66 & $21.7(20.1,22.7)$ & 4.1 \\
\hline Unoccupied during weekend evenings & 117 & $23.3(22.6,23.9)$ & 3.7 & 93 & $22.0(21.1,22.9)$ & 4.4 \\
\hline Highly variable & 52 & $22.7(21.6,23.7)$ & 3.7 & 40 & $21.7(21.2,22.7)$ & 4.2 \\
\hline \multicolumn{7}{|c|}{ Motivation, behaviour, perception characteristics } \\
\hline \multicolumn{7}{|c|}{ How easy or difficult is it for you to afford your energy bills } \\
\hline Very easy & 15 & $23.3(21.4,25.2)$ & 3.4 & 14 & $21.5(18.9,24.1)$ & 4.4 \\
\hline Fairly easy & 43 & $23.0(21.9,24.0)$ & 3.4 & 34 & $21.1(19.6,22.5)$ & 4.2 \\
\hline Neither easy nor difficult & 72 & $23.7(22.8,24.6)$ & 3.7 & 65 & $22.4(21.4,23.5)$ & 4.3 \\
\hline Fairly difficult & 40 & $23.7(22.3,24.4)$ & 3.3 & 32 & $21.5(19.9,23.0)$ & 4.3 \\
\hline Very difficult & 14 & $23.5(21.4,25.5)$ & 3.5 & 11 & $21.8(19.124 .4)$ & 4.0 \\
\hline \multicolumn{7}{|l|}{ I am worried about my energy bills } \\
\hline Strongly agree & 23 & $24.1(22.6,25.6)$ & 3.5 & 19 & $22.4(20.1,24.7)$ & 4.8 \\
\hline Tend to agree & 68 & $23.5(22.7,24.3)$ & 3.4 & 58 & $21.7(20.5,22.8)$ & 4.3 \\
\hline Neither agree nor disagree & 37 & $23.3(22.1,24.6)$ & 3.7 & 29 & $22.5(21.0,24.1)$ & 4.1 \\
\hline Tend to disagree & 21 & $23.4(21.9,25.0)$ & 3.3 & 19 & $21.4(19.3,23.5)$ & 4.4 \\
\hline Strongly disagree & 24 & $22.7(21.1,24.3)$ & 3.8 & 23 & $20.9(19.0,22.7)$ & 4.3 \\
\hline
\end{tabular}




\begin{tabular}{|c|c|c|c|c|c|c|}
\hline \multirow[b]{2}{*}{ Characteristics } & \multicolumn{3}{|c|}{ Reported winter heating TRV setting in living rooms $\left({ }^{\circ} \mathrm{C}\right)$} & \multicolumn{3}{|c|}{ Reported winter heating TRV setting in bedrooms $\left({ }^{\circ} \mathrm{C}\right)$} \\
\hline & $\mathrm{n}$ & Mean $(95 \% \mathrm{Cl})$ & SD & $\mathrm{n}$ & Mean $(95 \% \mathrm{Cl})$ & SD \\
\hline Strongly agree & 14 & $24.6(22.5,26.7)$ & 3.6 & 11 & $24.1(21.1,27.0)$ & 4.4 \\
\hline Tend to agree & 47 & $23.2(22.3,24.0)$ & 3.0 & 42 & $21.3(20.1,22.5)$ & 3.8 \\
\hline Neither agree nor disagree & 42 & $24.2(23.1,25.4)$ & 3.6 & 34 & $22.2(20.4,23.8)$ & 5.0 \\
\hline Tend to disagree & 26 & $23.7(22.3,25.2)$ & 3.6 & 21 & $21.5(19.6,23.5)$ & 4.4 \\
\hline Strongly disagree & 32 & $22.4(21.0,23.7)$ & 3.7 & 32 & $21.5(20.0,23.1)$ & 4.3 \\
\hline \multicolumn{7}{|c|}{ I often think about how I could save energy } \\
\hline Strongly agree & 51 & $23.4(22.5,24.4)$ & 3.4 & 40 & $22.4(21.3,23.5)$ & 3.4 \\
\hline Tend to agree & 81 & $23.5(22.8,24.3)$ & 3.6 & 72 & $21.5(20.3,22.6)$ & 4.8 \\
\hline Neither agree nor disagree & 22 & $23.6(22.2,25.1)$ & 3.2 & 20 & $21.9(19.8,24.1)$ & 4.6 \\
\hline Tend to disagree & 8 & $22.7(19.0,26.3)$ & 4.4 & 5 & $23.9(20.5,27.3)$ & 2.8 \\
\hline Strongly disagree & 12 & $22.3(20.0,24.5)$ & 3.5 & 11 & $20.0(17.9,22.0)$ & 3.1 \\
\hline \multicolumn{7}{|c|}{ I have control over how much energy is used in my home } \\
\hline Strongly agree & 46 & $22.1(21.1,23.0)$ & 3.0 & 36 & $20.7(19.6,21.7)$ & 3.1 \\
\hline Tend to agree & 68 & $23.7(22.9,24.5)$ & 3.4 & 58 & $22.2(21.1,23.4)$ & 4.4 \\
\hline Neither agree nor disagree & 40 & $23.3(22.1,24.6)$ & 3.9 & 32 & $21.5(19.7,23.3)$ & 4.9 \\
\hline Tend to disagree & 15 & $24.6(22.7,26.4)$ & 3.4 & 15 & $22.1(19.6,24.5)$ & 4.4 \\
\hline Strongly disagree & 5 & $25.1(21.0,29.2)$ & 3.3 & 6 & $23.6(18.6,28.6)$ & 4.8 \\
\hline \multicolumn{7}{|c|}{ I am not able to save any more energy } \\
\hline Strongly agree & 18 & $23.7(22.2,25.2)$ & 3.1 & 14 & $22.4(20.2,24.6)$ & 3.8 \\
\hline Tend to agree & 62 & $23.7(22.8,24.6)$ & 3.6 & 54 & $21.8(20.6,23.0)$ & 4.5 \\
\hline Neither agree nor disagree & 48 & $23.3(22.3,24.4)$ & 3.5 & 39 & $21.5(20.0,22.9)$ & 4.4 \\
\hline Tend to disagree & 22 & $23.4(21.8,25.1)$ & 3.6 & 24 & $21.1(19.2,23.6)$ & 4.6 \\
\hline Strongly disagree & 11 & $22.0(19.6,24.3)$ & 3.5 & 10 & $21.4(19.1,25.4)$ & 3.1 \\
\hline \multicolumn{7}{|c|}{ I make sure the curtains/blinds are closed when the heating is on in the evening } \\
\hline Always & 112 & $23.3(22.7,23.9)$ & 3.3 & 92 & $21.7(20.9,22.5)$ & 3.9 \\
\hline Often & 41 & $23.9(22.7,25.1)$ & 3.8 & 36 & $21.7(20.0,23.4)$ & 5.0 \\
\hline Sometimes & 19 & $24.3(22.6,26.0)$ & 3.5 & 17 & $23.0(20.5,25.5)$ & 4.9 \\
\hline Very occasionally & 3 & $24.6(14.5,34.7)$ & 4.1 & 3 & $22.6(11.4,33.8)$ & 4,5 \\
\hline Never & 9 & $22.6(20.0,25.2)$ & 3.4 & 8 & $23.4(20.2,26.6)$ & 3.9 \\
\hline \multicolumn{7}{|c|}{ I make sure the curtains/blinds are open when the sun is shining in winter } \\
\hline Always & 141 & $23.7(23.1,24.2)$ & 3.3 & 121 & $22.1(21.3,22.8)$ & 4.1 \\
\hline Often & 31 & $23.1(21.7,24.4)$ & 3.7 & 25 & $21.0(19.1,23.0)$ & 4.7 \\
\hline Sometimes & 9 & $24.1(21.5,26.8)$ & 3.4 & 7 & $23.9,(20.3,27.5)$ & 3.9 \\
\hline Very occasionally & 3 & $17.3(11.4,23.1)$ & 2.4 & 3 & $17.3(11.4,23.1)$ & 2.4 \\
\hline Never & 1 & 23.9 & & 1 & 27.8 & \\
\hline \multicolumn{7}{|c|}{ I make sure the windows are closed when the heating is on } \\
\hline Always & 141 & $23.7(23.2,24.3)$ & 3.4 & 118 & $22.3(21.6,23.1)$ & 4.0 \\
\hline Often & 28 & $23.6(22.1,25.0)$ & 3.6 & 26 & $20,7(18.6,22.8)$ & 5.3 \\
\hline Sometimes & 14 & $21.1(19.1,23.0)$ & 3.4 & 12 & $20.5(18.3,22.6)$ & 3.4 \\
\hline Very occasionally & 2 & $22.0(-2.8,46.7)$ & 2.8 & 1 & 27.8 & \\
\hline \multicolumn{7}{|c|}{ I close the doors between rooms } \\
\hline Always & 67 & $23.1(22.3,24.0)$ & 3.5 & 53 & $22.3(21.2,23.4)$ & 4.0 \\
\hline Often & 35 & $23.8(22.6,25.0)$ & 3.5 & 31 & $22.1(20.5,23.7)$ & 4.4 \\
\hline Sometimes & 36 & $24.0(23.0,25.0)$ & 3.0 & 36 & $21.3(19.8,22.8)$ & 4.5 \\
\hline Very occasionally & 14 & $24.2(21.9,26.4)$ & 3.9 & 11 & $23.2(19.8,25.5)$ & 5.0 \\
\hline Never & 28 & $23.3(21.9,24.7)$ & 3.6 & 21 & $21.7(19.8,23.6)$ & 4.1 \\
\hline
\end{tabular}




\begin{tabular}{|c|c|c|c|c|c|c|}
\hline \multirow[b]{2}{*}{ Characteristics } & \multicolumn{3}{|c|}{ Reported winter heating TRV setting in living rooms $\left({ }^{\circ} \mathrm{C}\right)$} & \multicolumn{3}{|c|}{ Reported winter heating TRV setting in bedrooms $\left({ }^{\circ} \mathrm{C}\right)$} \\
\hline & $\mathrm{n}$ & Mean $(95 \% \mathrm{Cl})$ & SD & $\mathrm{n}$ & Mean $(95 \% \mathrm{Cl})$ & SD \\
\hline \multicolumn{7}{|c|}{ I wear very warm clothes in winter so I can keep the heating low or off } \\
\hline Always & 78 & $23.6(22.8,24.4)$ & 3.5 & 65 & $22.7(21.6,23.8)$ & 4.3 \\
\hline Often & 55 & $23.0(22.0,24.0)$ & 3.8 & 48 & $20.5(19.3,21.7)$ & 4.1 \\
\hline Sometimes & 32 & $24.5(23.4,25.6)$ & 3.1 & 29 & $22.7(21.1,24.4)$ & 4.3 \\
\hline Very occasionally & 9 & $23.7(21.9,25.5)$ & 2.3 & 5 & $21.2(16.3,26.0)$ & 3.9 \\
\hline \multirow{2}{*}{\multicolumn{7}{|c|}{ I change the temperature on my thermostat }} \\
\hline & & & & & & \\
\hline Always & 79 & $23.6(22.8,24.4)$ & 3.4 & 70 & $21.9(20.9,22.9)$ & 4.1 \\
\hline Often & 38 & $23.2(21.9,24.4)$ & 3.8 & 35 & $21.2(19.7,22.7)$ & 4.3 \\
\hline Sometimes & 35 & $23.9(22.8,25.1)$ & 3.3 & 27 & $22.6(20.6,24.5)$ & 4.9 \\
\hline Very occasionally & 8 & $23.2(20.2,26.2)$ & 3.6 & 5 & $20.7(15.4,26.1)$ & 4.3 \\
\hline Never & 15 & $23.5(21.4,25.6)$ & 3.9 & 12 & $24.6(22.4,26.7)$ & 3.4 \\
\hline \multicolumn{7}{|c|}{ I turn the heating off when no one is at home } \\
\hline Always & 133 & $23.5(22.9,24.1)$ & 3.5 & 115 & $22.2(21.4,23.0$ & 4.2 \\
\hline Often & 23 & $24.0(22.5,25.5)$ & 3.4 & 20 & $21.0(18.7,23.3)$ & 4.9 \\
\hline Sometimes & 18 & $23.0(21.6,24.5)$ & 2.9 & 14 & $21.9(19.8,24.1)$ & 3.7 \\
\hline Very occasionally & 6 & $22.0(18.5,25.4)$ & 3.3 & 6 & $18.6(14.2,23.0)$ & 4.2 \\
\hline Never & 6 & $23.0(19.3,26.6)$ & 3.5 & 3 & $24.6(14.5,24.7)$ & 4.1 \\
\hline \multicolumn{7}{|c|}{ I turn off the heating in rooms that are not normally used } \\
\hline Always & 77 & $22.9(22.1,23.6)$ & 3.4 & 50 & $22.2(21.1,23.4)$ & 4,2 \\
\hline Often & 30 & $23.5(22.1,24.9)$ & 3.7 & 28 & $19.9(18.1,21.6)$ & 4.5 \\
\hline Sometimes & 24 & $24.5(23.2,25.8)$ & 3.1 & 26 & $22.3(20.6,24.0)$ & 4.2 \\
\hline Very occasionally & 15 & $23.0(20.9,25.0)$ & 3.7 & 14 & $20.9(18.9,23.0)$ & 3.5 \\
\hline Never & 27 & $23.7(22.4,25.1)$ & 3.4 & 26 & $23.2(21.6,24.8)$ & 3.9 \\
\hline \multicolumn{7}{|c|}{ I adjust the temperature on my radiators } \\
\hline Always & 56 & $23.1(22.1,24.0)$ & 3.5 & 46 & $21.9(20.8,23.1)^{\star *}$ & 4.0 \\
\hline Often & 38 & $22.4(21.3,23.4)^{\star * *}$ & 3.2 & 32 & $20.1) 18.8,21.5)^{\star * *}$ & 3.7 \\
\hline Sometimes & 45 & $23.5(22.4,24.6)$ & 3.7 & 40 & $21.4(19.8,22.9)^{\star *}$ & 4.7 \\
\hline Very occasionally & 17 & $24.7(23.2,26.2)$ & 2.9 & 14 & $22.5(20.1,24.8)$ & 4.1 \\
\hline Never & 25 & $25.3(24.1,26.5)^{\star \star \star}$ & 3.0 & 22 & $25.1(23.7,26.5)^{\star \star *}$ & 3.2 \\
\hline
\end{tabular}

*Significant at the $5 \%$ level $(p=0.05)$

${ }^{*}$ Significant at the $1 \%$ level $(p=0.01)$

${ }^{* *}$ Significant at the $0.1 \%$ level $(p=0.001)$ 


\subsection{Comparison between whole house thermostat setting and TRV setpoint temperatures}

An analysis was conducted to compare the TRV setpoint temperatures used in living rooms and bedrooms with the whole house thermostat setpoint temperatures used by social housing residents. Table 5 shows the overall mean thermostat setpoint temperatures and TRV settings in the living room and bedroom.

Table 5 Comparison between mean winter whole house thermostat setting and living room and bedroom TRV setpoint temperatures

\begin{tabular}{|c|c|c|c|c|c|}
\hline & & \multicolumn{2}{|c|}{$\begin{array}{l}\text { Whole house thermostat } \\
\text { setpoint temperature }\left(^{\circ} \mathrm{C}\right)\end{array}$} & \multicolumn{2}{|c|}{$\begin{array}{l}\text { TRV setpoint temperature } \\
\left({ }^{\circ} \mathrm{C}\right)\end{array}$} \\
\hline & $\mathbf{n}$ & Mean $(95 \% \mathrm{Cl})$ & SD & Mean $(95 \% \mathrm{Cl})$ & SD \\
\hline All living rooms & 144 & $20.7(20.2,21.2)$ & 2.8 & $23.4(22.8,24.0)$ & 3.6 \\
\hline All bedrooms & 120 & $20.9(20.4,21.4)$ & 2.7 & $22.1(21.1,22.7)$ & 4.4 \\
\hline
\end{tabular}

Out of the 187 households that reported a living room TRV setting, 144 reported thermostat settings. Across the whole sample, the mean whole house thermostat setpoint temperature was $20.7^{\circ} \mathrm{C}(\mathrm{SD}=$ 2.8) but the living room $T R V$ setpoint temperature was set much higher at $23.4^{\circ} \mathrm{C}(S D=3.6)$. From the 144 households, 34 households had set their living room TRV to a setpoint which was lower than their thermostat, 94 households had a higher TRV setting, and 16 had the same setting for the TRV and thermostat. In the households where the TRV setpoint was the same as the thermostat setpoint, the temperature was set to $20^{\circ} \mathrm{C}$. In cases where the TRV setting was lower than the thermostat, the average difference was $3^{\circ} \mathrm{C}$, the average TRV setpoint was $20^{\circ} \mathrm{C}$ and thermostat was $23^{\circ} \mathrm{C}$. Where the TRV setpoint was higher than the thermostat, the TRVs were on average set to $5^{\circ} \mathrm{C}$ higher than the thermostat setting, with the average TRV set to $25^{\circ} \mathrm{C}$ and thermostat to $20.0^{\circ} \mathrm{C}$.

From the 159 households that reported bedroom TRV settings, 120 provided thermostat settings. Across this sample, the mean whole house thermostat setpoint temperature was $20.9^{\circ} \mathrm{C}(\mathrm{SD}=2.7)$ and the bedroom TRV setpoint temperature was $22.1^{\circ} \mathrm{C}(\mathrm{SD}=4.4)$. Out of the 120 households, 48 had their bedroom TRVs set to a lower setpoint temperature than the whole house thermostat, 56 had higher TRV setpoint temperatures and 16 had the same settings on both TRV and thermostat. In households with lower bedroom TRV settings, there was an average $4^{\circ} \mathrm{C}$ difference, with the average thermostat setpoint temperature set to $22^{\circ} \mathrm{C}$ and the bedroom TRV set to $18^{\circ} \mathrm{C}$. Where the thermostat setting was lower than the TRV setting, the average setpoint temperatures were $20^{\circ} \mathrm{C}$ and $26^{\circ} \mathrm{C}$ respectively. In households where both settings were identical, the setpoint temperatures were $21^{\circ} \mathrm{C}$.

\section{Discussion}

\subsection{Living room and bedroom TRV settings in UK social housing}

The findings reported in this paper suggest that there are variations in social housing tenants' use of TRVs and thus space heating behaviour depending on the room within a dwelling. This finding is consistent with the assumption used in BREDEM-based models where the living room temperature is set at $21^{\circ} \mathrm{C}$ and the bedroom temperature is set at $18^{\circ} \mathrm{C}$ [35] as well as with the work carried out by Kane et al. [26] which found lower temperatures in the bedroom $\left(\mathrm{M}=17.4^{\circ} \mathrm{C}, \mathrm{SD}=2.9\right)$ than the living room $\left(M=18.5^{\circ} \mathrm{C}, S D=3.0\right)$. Some statistically significant relationships between the TRV setpoint temperatures used in living rooms and bedrooms and dwelling, household, and motivation, behaviour and perception characteristics were found and some observations and discussions stemming from the analysis are presented below.

Overall, the mean TRV settings of the sample were $23.4^{\circ} \mathrm{C}$ and $21.9^{\circ} \mathrm{C}$ in the living room and the bedroom respectively. Although these values are higher than those used in the BREDEM-based models and those reported by [34] Kane et al., [26] they indicate that bedrooms are generally cooler than living rooms. The data collected in the study presented in this paper showed that not all bedrooms were heated, $15 \%$ of respondents reported a ' 0 ' TRV setting and one reported using the frost protection setting, indicating that the radiator only comes on when the internal temperature falls below $6.9^{\circ} \mathrm{C}$. All 
TRVs in the living rooms were reported to be in use with settings ranging from 1 to 6 , implying that during the heating season, all living rooms were potentially heated depending on the internal temperature. The difference in TRV settings in the living rooms and the bedrooms is consistent with the findings from the study of occupant heating setpoint preferences in Danish dwellings where some residents in their case study dwellings reported that they never turned on the heating in the bedroom [33]. Regarding the thermostat setpoint temperature, the result obtained in the current study confirms that on average thermostat setpoint temperatures in social housing are similar to those used in the wider housing stock. The mean setpoint value obtained is also similar to the $21.0^{\circ} \mathrm{C}$ recommended by the World Health Organisation (WHO) as a comfortable indoor temperature and to prevent potential negative health effects [28].

TRVs control heating demand temperatures in individual rooms within a dwelling. It is the whole house thermostat that controls the heating system overall. Using TRVs to set cooler thermal conditions in different spaces than the whole house thermostat setting has the potential to reduce space heating energy demand, as the length of heating periods will be reduced. Note that in zones where the TRV setpoint temperature is higher than the whole house thermostat, the TRV setpoint temperature becomes redundant as it will not be reached before the heating is turned off by the whole house thermostat setpoint. If the TRVs are being used in this manner, which was evident in $65 \%$ of the households (of households that reported living room TRV settings and thermostat settings) in the current study, it implies that social housing residents may not understand the role of TRVs in the home heating system and thus their energy saving potential. This finding may also suggest that perhaps social housing tenants would prefer warmer conditions in their homes than what their overriding thermostat permits. The TRV setting might be a true reflection of the thermal conditions residents' desire.

The results obtained from the comparison of the whole house thermostat setpoint temperatures and the TRV setpoint temperatures presented in this paper showed that more often than not, the TRVs were set higher than the thermostat. This was more prevalent in living rooms than bedrooms. In the bedrooms, including the radiators that were turned off, half of the TRVs (71 out of 143) were set to a lower temperature than the thermostat; on average maintaining temperatures of about $4^{\circ} \mathrm{C}$ lower than the whole house setpoint temperature.

\subsection{Setpoint temperatures in relation to dwelling characteristics}

The results obtained for the dwelling characteristics provide evidence of the impact of factors such as dwelling type and size and insulation levels on space heating behaviours. On average, living room TRV settings were lower in mid terraced dwellings. This could be because mid terraced houses only have two exposed walls, hence reducing heat loss through infiltration compared to end terraced and semidetached dwellings. As mid terraces are able to retain more heat, the living room TRV can be set to a lower setpoint temperature to maintain comfortable thermal conditions.

Respondents in dwellings with three floors reported using higher TRV settings in living rooms and bedrooms compared to those with one or two floors. Air when heated becomes less dense and rises, hence in dwellings with uninsulated floors, heated air will escape into the floors above. To maintain comfortable thermal conditions, occupants may need to set the TRVs on ground and first floors to higher settings in an attempt to achieve higher temperatures. In most dwellings, the living rooms are on the ground floor hence this could be a possible reason for the higher TRV settings.

In bedrooms, TRV settings were generally cooler in dwellings with at least $250 \mathrm{~mm}$ thickness of roof insulation. The possible explanation for this could be that having roof insulation minimises heat loss through the roof and retains the heat in the dwelling. Furthermore, this result is consistent with the fact that dwellings with the lowest SAP ratings (i.e. the least thermally efficient homes) also had the highest living room TRV setpoint temperatures. There was very little difference in TRV setpoint temperatures in dwellings with thermal upgrades (retrofitted cavity or solid wall insulation) and those without (as-built). These findings regarding presence of thermal upgrades and SAP rating are in contrast to findings from previous work which assessed their effects on the whole house thermostat setpoint temperatures [12], 
and suggested that occupants may have higher thermostat settings in more thermally efficient homes (i.e. the rebound or take-back effect).

TRV settings varied according to the type of heating system installed. Dwellings with condensing combi boilers reported lower TRV setpoint temperatures in both the living rooms and bedrooms compared to dwellings with standard combi boilers. Condensing boilers are more efficient as they capture and reuse some of the waste heat, hence providing more heat from the same amount of fuel. Householders may therefore turn down the TRV setting to prevent excessive heat during the heating period.

\subsection{Setpoint temperatures in relation to household and occupancy characteristics}

The results obtained for the effects of household characteristics showed that households with five or more occupants had the highest living room TRV settings. This finding was mirrored in the result that households with couples with dependent children have the highest TRV settings.

Lone parent families were found to have cooler TRV settings than all other household compositions. In the living room, the mean TRV setpoint temperatures $\left(22.2^{\circ} \mathrm{C}\right)$ were higher than the $21^{\circ} \mathrm{C}$ recommended by the $\mathrm{WHO}$ and in the bedroom $\left(20.7^{\circ} \mathrm{C}\right)$ which is consistent with the WHO recommendation. However, in the coldest $5 \%$ of dwellings occupied by lone parent families, the TRV setpoint temperatures were $19.4^{\circ} \mathrm{C}$ and $15.4^{\circ} \mathrm{C}$ in the living rooms and bedrooms respectively. This finding is consistent with the study of thermostat settings [12] which found that lone parent families had cooler thermostat settings than other household compositions. The result may reflect the lower average household incomes of lone parent families. The heating behaviour of lone parent families living in social housing and the consequent health impacts could be an area for further investigation and should potentially be of concern for government policy makers as well as local authority and social housing associations.

Regarding employment structure, TRV settings were lowest in households with unemployed members, indicating a possible impact of household income on space heating behaviours. Also, the TRV settings in both rooms were lower than the thermostat setting. This indicates that households with unemployed members may be trying to save money by adjusting their TRVs.

Lower bedroom setpoint temperatures were also reported in the homes of HRPs who considered their general health in the last 12 months as bad and those who reported visiting the GP 7 to 12 times in the past year. Bad health may limit the HRP's potential to work, hence reducing the household income so having lower bedroom setpoint temperatures may be their attempt to reduce their heating bill. Alternatively, lower bedroom temperatures may contribute to the bad health of the HRP and the increased number of GP visits (the lower $95 \% \mathrm{Cl}$ indicated that $5 \%$ of the respondents who visited the GP 7-12 times a year reported a TRV setting of $16.7^{\circ} \mathrm{C}$ or below). Although the effect of household income on TRV setpoint temperatures was not directly investigated, as the household survey did not ask respondents to report their annual household income. Previous studies have identified significant effects of income on space heating behaviour [52]-[55]. The question of household income was considered too sensitive as the study focussed on social housing residents who typically are a lowincome group.

Living room and bedroom TRV setpoint temperatures were higher in households that received welfare benefits. There was no evident difference between the setpoint temperatures in households with or without disabled members. These findings are in contrast to the findings from the work on thermostat settings [12], [53] which showed that households with vulnerable members had lower setpoint temperatures.

There were no evident relationships between TRV setpoint temperatures and households that were either occupied or unoccupied during weekdays or weekend daytimes or evenings. Ideally, during periods when homes are not occupied, households would reduce their TRV setpoint temperatures or turn off the heating in order to reduce their heating energy use. A possible reason could be that occupants may find it inconvenient to go round the house turning off the TRVs each time they leave the house. From a survey of 273 participants, Huebner et al. [56] reported that householders did not make 
use of the control opportunities provided by TRVs and some of the reasons could be the perceived effort of using TRVs, the demand for similar temperatures in all rooms or a lack of knowledge about the importance of using TRVs. The usability of heating controls has also been reported as having an influence on heating behaviours [57]. TRV settings are displayed in numbers ranging from 0-5/6 and not temperatures like on a thermostat. Householders may therefore not be aware of the corresponding setpoint temperatures for the levels on the TRV. If this is the case then householders may not know that the TRV setting is redundant if it is higher than thermostat setting. The findings of the current study suggest that households living in social housing may not be aware of the energy saving potential of TRVs and are currently missing out on reducing their heating energy demand and consequently their heating bills.

\subsection{Setpoint temperatures in relation to motivation, behaviour and perception characteristics}

In relation to how difficult it was for the social housing residents to afford their energy bills, there were small differences in TRV settings observed with those who reported finding it neither easy nor difficult having the highest TRV settings. In the living room, their average setpoint temperature was $0.7^{\circ} \mathrm{C}$ higher than the lowest setpoint temperature in the category (fairly easy) and in the bedroom, their average setpoint temperature was $1.4^{\circ} \mathrm{C}$ higher. Households that strongly agreed that they were worried about their energy bills had the highest average TRV setting in living rooms $\left(24.1^{\circ} \mathrm{C}\right)$ and the second highest in bedrooms $\left(22.4^{\circ} \mathrm{C}\right)$. In addition, in households where members strongly agreed that they did not understand how their homes used energy had warmer living rooms $\left(24.6^{\circ} \mathrm{C}\right)$ and bedrooms $\left(24.1^{\circ} \mathrm{C}\right)$ and households that strongly agreed to not being able to save any more energy also had higher living room and bedroom TRV settings $\left(23.7^{\circ} \mathrm{C}\right.$ and $\left.22.4^{\circ} \mathrm{C}\right)$. Householders who strongly agreed to having control over how much energy they used at home had the coolest living rooms $\left(22.1^{\circ} \mathrm{C}\right)$ and bedrooms $\left(20.7^{\circ} \mathrm{C}\right)$. These findings suggest that by improving understanding and engagement in energy efficiency at home, households may respond by lowering their heating setpoint temperatures, resulting in reductions in heating energy use. However, the results currently suggest that in spite of some social housing tenants appearing to be conscious of their potential to reduce their energy use, this does not translate into energy saving actions related to heating behaviour. It has been reported that occupants' use of heating controls is often driven by a desire to achieve thermal comfort rather than a wish to save energy [58].

Interestingly, where the social housing residents said they never adjusted the temperature on their radiators, the setpoint temperatures were higher in both living rooms $\left(25.3^{\circ} \mathrm{C}\right)$ and bedrooms $\left(25.1^{\circ} \mathrm{C}\right)$. Where householders said they never turn off the heating in rooms that are not normally used, the average setpoint temperatures in the living rooms and bedrooms were both $1^{\circ} \mathrm{C}$ higher than those who said they always turned the heating off. These findings suggest that there is scope for households living in social housing to reduce their heating energy use by adjusting their habits. Actively using the TRVs to adjust room temperature and control heating will result in savings on heating energy demand.

Householders who said they very occasionally turn the heating off when no one is at home had the lowest setpoint temperatures in the living rooms, which were also lower than the thermostat setpoint temperatures. Those who said they always/often turned the heating off had the highest TRV setpoint temperatures. One possible reason for these results could be the general misunderstanding that it is better to leave the heating on continuously at low temperatures rather than to turn it off/on as the boiler has to work harder to heat the dwelling from cold. Although, it has been shown that the use of a programmable thermostat and TRVs can decrease heating energy demand [42], [43], [59]-[62], it is also noted that the savings are not necessarily achieved unless the user has knowledge about the operation of the control mechanisms [9], [56], [57], [63]. Furthermore, social housing tenants may simply not be aware of the additional behaviours that can help to reduce their heating energy demand and heating bills.

\subsection{Applications for the research}


The research reported in this study should be of interest to a number of key groups, including, government policy makers, local authorities managing social housing, social housing associations, energy supply companies, designers of heating controls, as well as energy modellers.

A key finding from the research is that a significant percentage of the households living in social housing in this study set higher TRV settings in their living rooms and bedrooms than their whole house thermostat setting, indicating that perhaps they do not fully understand the role of TRVs, i.e. the TRV setting has to be lower than the thermostat setting to be useful and reduce space heating energy demands. This is important for the future design of heating controls. There is an inference here for the design and usability of TRV devices and this study can inform technology developers in their design of energy efficiency devices which are installed as part of interventions for reducing energy use in homes.

Local authorities and housing associations, as well as local and national government could use these findings to target energy campaigns aimed at improving the understanding of heating behaviour at home. This may help householders to better use devices such as TRVs and thermostats, resulting in reductions in heating energy use.

Furthermore, more thermally efficient dwellings, either new-build or which had undergone thermal upgrades such as increasing wall and roof insulation, were observed to have positive influences on space heating behaviours (i.e. lower TRV settings used by occupants). The installation of thermal upgrades through retrofit could be used by local authorities and social housing associations as a possible route to not only improving the thermal efficiency of the fabric of their social housing stock but also as a method for encouraging behaviour change amongst their tenants.

The results provided by this paper highlight the dwelling, household, and motivation, behaviour and perception characteristics affecting TRV use in living rooms and bedrooms. Further research into how TRVs are being used (in other dwelling zones, frequency of adjustment and factors influencing their use), will be required to further enhance our understanding of occupant zonal heating control behaviours. The current findings can be used to provide an initial picture of the variation in space heating behaviours within social housing and could be extrapolated to the wider social housing stock to provide indications of how space heating demands might change as the building stock and the socio-economic profile of the householders evolves in future. The characteristics associated with higher TRV settings could be mapped on to other UK national datasets to identify hot-spots of where high heat demand may exist, this may be useful to energy supply companies and energy distribution network operators for the future planning of heat networks and defining their necessary capacity.

The findings obtained in this work also have implications for the energy modelling of UK social housing. The data presented in this paper could be used to assist the energy modelling community for predicting the space heating demands of social housing and the potential energy savings from refurbishment measures. Recent studies [24] have stated that there is little guidance regarding the values that should be assigned for energy modelling of domestic buildings and that standardised heating patterns in Simplified Building Energy Models (SBEM) misrepresent the variability of heating preferences in real homes [9], [24], [26], [27], [36]. In addition to variations between homes, studies have also shown that there is variation in heating setpoints from room to room within a dwelling [26], [33]. The current work further corroborates these sentiments. Whilst the average whole house thermostat setpoint temperature matched well with values recommended in a number of previous household heating studies [9], [11], [12], [26], [34], the assessment of living room and bedroom TRV settings show that in some cases, householders specify lower setpoint temperatures in individual rooms and these are not reflected by the whole house thermostat setting often used in building models.

\subsection{Limitations and future research}

The results obtained in this study are based on relatively small sample sizes (TRV setpoint temperatures for 187 living rooms and 159 bedrooms) from a single UK city and therefore extrapolating 
the results to the wider population of UK social housing or owner-occupied or privately rented homes is not appropriate. A larger national-scale study of heating setpoint temperatures in individual rooms in UK social housing would therefore be a valuable extension to the current work and could also be used to validate the findings of the current study. Previous UK studies at the national [64] and city-scales [65] have primarily excluded the social housing stock in their analyses and have excluded a detailed assessment of the factors influencing TRVs settings. Therefore these data offer a valuable contribution to the field.

The reliability of the self-report data provided by the survey participants is an overarching concern for all energy use surveys. Previous studies have found inconsistencies between self-reported and actual thermostat settings used in homes [9]. The accuracy of the data may be affected by the respondents' inability to remember their TRV setpoint temperatures as well as their intentional under-reporting to appear more energy efficient, in order to please the researchers or to conform with others (social desirability bias). In addition, heating setpoint temperatures, both thermostat and TRV, can change over time. A number of recent studies are developing techniques to overcome this issue, such as using high resolution indoor air temperature measurements to infer heating setpoints in homes $[9,24,26,27,36]$ and requesting households to upload photographs of their thermostats using crowdsourcing services [30]. As noted in the BS EN ISO 13790 standard [66], using indoor temperature data however to infer heating setpoints, should be done with caution as "internal temperature is not the same as the setpoint due to effects such as overheating, intermittency, inertia, imperfect control".

To date, research undertaking direct measurements of thermostat and TRV settings in homes has been limited by the availability of commercial/off-the-shelf monitoring equipment. To the authors' knowledge, Andersen et al.'s [33] study in Denmark which developed a custom monitoring device, is the only study to provide direct measurement of TRV setpoints in homes. However, with the rapid development of 'smart' Internet-connected thermostats and TRVs, which allow users to control their heating via a website or on their smart phone, data about space heating behaviours will become increasing available for further research in this field.

Following on from this study and previous studies on occupant heating behaviour, a recommendation for future work would be to implement the setpoint temperatures for the whole house and for individual zones into building performance simulation tools. These temperature values may result in more realistic predictions of the space heating energy demand of social housing, as they specifically relate to dwelling characteristics (e.g. type, age, level of insulation), household demographics (e.g. size, composition, occupancy patterns) and household motivation, behaviour and perception characteristics (e.g. affordability of energy bill, energy understanding, ventilation behaviour, etc.). This can then lead to the design and implementation of the most effective energy efficient interventions based on the assessed characteristics.

\section{Conclusions}

This paper provides an analysis of the relationships between dwelling, household, and motivation, behaviour and perception characteristics and living room and bedroom TRV setpoint temperatures. The paper also provides a comparison of the TRV settings used in these individual rooms with the whole house thermostat setpoint temperature. The data analysed in this study were derived from a sociotechnical household survey undertaken in Plymouth, UK, during 2015, as part of the EnerGAware project. The data collected from the survey were merged with building audit records held by the households' social housing association, which contained a comprehensive overview of the key structural elements and services in each home, as well as the dataset for the RdSAP energy rating methodology.

Overall, the mean winter TRV setting in the living room was $23.4^{\circ} \mathrm{C}$ and $21.9^{\circ} \mathrm{C}$ in the bedroom. The results of this study suggest that there is variation in how social housing tenants control their heating within their homes and that there is great variation among dwellings. Not all the relationships were clear and/or strong; however, there were some systematic variations according to dwelling, household, and 
motivation, behaviour and perception characteristics. In living rooms in end terrace dwellings, the mean TRV setting was $24.5^{\circ} \mathrm{C}$ and in mid terrace dwellings, it was $22.3^{\circ} \mathrm{C}$. Also in living rooms in inefficient dwellings (SAP rating E-G), the mean TRV setting was $24.8^{\circ} \mathrm{C}$ and in dwellings with higher energy efficiency ratings (SAP rating $\mathrm{B}$ ), it was $22.5^{\circ} \mathrm{C}$. Households where couples lived with dependent children had the highest mean TRV settings in the bedrooms $\left(25.4^{\circ} \mathrm{C}\right)$ whereas lone parent households had the lowest $\left(20.7^{\circ} \mathrm{C}\right)$. Households who strongly agreed that they did not understand how their home used energy had higher mean living room TRV settings $\left(24.6^{\circ} \mathrm{C}\right)$ than those who strongly disagreed $\left(22.7^{\circ} \mathrm{C}\right)$.

The results confirmed that householders prefer cooler thermal conditions in bedrooms $\left(21.9^{\circ} \mathrm{C}\right)$ than living rooms $\left(23.4^{\circ} \mathrm{C}\right)$. However, in general, the TRV setpoint temperatures in individual rooms were often higher than the setpoint temperature of the whole house thermostat. From the dwellings that reported both thermostat and living room TRV settings, the thermostat was set at a mean temperature of $20.7^{\circ} \mathrm{C}$ and the TRV was set at $23.4^{\circ} \mathrm{C}$. Similarly, from the dwellings that reported both thermostat and bedroom TRV settings, the mean temperature settings were $20.9^{\circ} \mathrm{C}$ and $22.1^{\circ} \mathrm{C}$ respectively. This may suggest a misunderstanding of the role of TRVs in the home heating system and as a result households living in social housing are missing the opportunity to reduce their space heating energy demands and associated energy bills.

Furthermore, the study identified that households do not prioritise reductions in their TRV settings as an energy efficiency action, even when they find it difficult to afford their energy bills or believe that they could save more energy or were worried about their bills. Those who reported finding it fairly difficult to afford their energy bills on average set their living room TRV at $23.7^{\circ} \mathrm{C}$ whereas those who found it fairly easy to afford their energy bills had a lower setting of $23.0^{\circ} \mathrm{C}$. Those who strongly agreed to being worried about their energy bills also on average reported higher living room and bedroom TRV settings $\left(24.1^{\circ} \mathrm{C}\right.$ and $\left.22.4^{\circ} \mathrm{C}\right)$ compared to those who strongly disagreed $\left(22.7^{\circ} \mathrm{C}\right.$ and $\left.20.9^{\circ} \mathrm{C}\right)$.

In light of these results, it is evident that additional research about households' understanding of heating controls is required, as well as the potential barriers to reducing heating setpoint temperatures at home. This would allow effective behaviour change interventions and energy efficiency campaigns to be designed.

The research reported in this study could enable social housing providers, the government and other commercial organisations to target energy efficiency measures (i.e. thermal upgrades) and social interventions (i.e. behaviour change) at those dwellings and households where their impact may be most beneficial.

Finally, the TRV setpoint data presented in this paper could be used to better inform the assumptions of occupant heating behaviours used in energy models (building performance simulation tools), which could result in more realistic predictions of the space heating demands of social housing and the potential energy savings from refurbishment measures.

\section{Acknowledgements}

The research reported in this paper was undertaken as part of the EnerGAware project: Energy Game for Awareness of energy efficiency in social housing communities. This project has received funding from the European Union's Horizon 2020 research and innovation programme under grant agreement No 649673.

The authors would like to thank $\mathrm{DCH}$ for sharing data held on their asset management and building stock condition database and their residents for participation in this study.

\section{References}


[1] DECC, "Emissions from Heat: Statistical Summary," London, 2012.

[2] HM Government, "Climate Change Act 2008," London, 2008.

[3] DECC, “United Kingdom housing energy fact file," London, 2013.

[4] Office of the Deputy Prime Minister, The Building Regulations 2000 Conservation of fuel and power in dwellings: Amendments to Approved Document L1. UK, 2005, pp. 0-8.

[5] J. I. Utley and L. D. Shorrock, "Domestic energy fact file 2008," Energy, pp. 1-99, 2008.

[6] E. Shove, Comfort, cleanliness and convenience: The social organisation of normality. Oxford: Berg, 2003.

[7] HM Government, "Domestic Building Services Compliance Guide," p. 96, 2013.

[8] Heating and Hot Water Task Force, "Heating and Hot Water Pathways to 2020," 2010.

[9] M. Shipworth, S. K. Firth, M. I. Gentry, A. J. Wright, D. T. Shipworth, and K. J. Lomas, "Central heating thermostat settings and timing: Building demographics," Build. Res. Inf., vol. 38, no. 1, pp. 50-69, 2010.

[10] V. Fabi, R. V. Andersen, and S. P. Corgnati, "Influence of occupant's heating set-point preferences on indoor environmental quality and heating demand in residential buildings," HVAC R Res., vol. 19, no. 5, pp. 635-645, 2013.

[11] G. M. Huebner, M. McMichael, D. Shipworth, M. Shipworth, M. Durand-Daubin, and A. Summerfield, "Heating patterns in English homes: Comparing results from a national survey against common model assumptions," Build. Environ., vol. 70, pp. 298-305, 2013.

[12] R. V. Jones, A. Fuertes, C. Boomsma, and S. Pahl, "Space heating preferences in UK social housing: A socio-technical household survey combined with building audits," Energy Build., vol. 127, pp. 382-398, 2016.

[13] R. Critchley, J. Gilbertson, M. Grimsley, and G. Green, "Living in cold homes after heating improvements: Evidence from Warm-Front, England's Home Energy Efficiency Scheme," Appl. Energy, vol. 84, no. 2, pp. 147-158, 2007.

[14] S. Karjalainen, "Gender differences in thermal comfort and use of thermostats in everyday thermal environments," Build. Environ., vol. 42, no. 4, pp. 1594-1603, 2007.

[15] R. V. Andersen, J. Toftum, K. K. Andersen, and B. W. Olesen, "Survey of occupant behaviour and control of indoor environment in Danish dwellings," Energy Build., vol. 41, no. 1, pp. 11$16,2009$.

[16] S. Yang, M. Shipworth, and G. Huebner, "His, hers or both's? The role of male and female's attitudes in explaining their home energy use behaviours," Energy Build., vol. 96, pp. 140-148, 2015.

[17] S. Kelly et al., "Predicting the diversity of internal temperatures from the English residential sector using panel methods," Appl. Energy, vol. 102, pp. 601-621, 2013.

[18] A. Schuler, C. Weber, and U. Fahl, "Energy consumption for space heating of West-German households: Empirical evidence, scenario projections and policy implications," Energy Policy, vol. 28, no. 12, pp. 877-894, 2000.

[19] O. Guerra Santin, L. Itard, and H. Visscher, "The effect of occupancy and building characteristics on energy use for space and water heating in Dutch residential stock," Energy Build., vol. 41, no. 11, pp. 1223-1232, 2009.

[20] T. Oreszczyn, S. H. Hong, I. Ridley, and P. Wilkinson, "Determinants of winter indoor temperatures in low income households in England," Energy Build., vol. 38, no. 3, pp. 245252, 2006.

[21] S. H. Hong, T. Oreszczyn, and I. Ridley, "The impact of energy efficient refurbishment on the space heating fuel consumption in English dwellings," Energy Build., vol. 38, no. 10, pp. 1171- 
1181, 2006.

[22] O. G. Santin, "Behavioural patterns and user profiles related to energy consumption for heating," Energy Build., vol. 43, no. 10, pp. 2662-2672, 2011.

[23] R. Andersen, "The influence of occupants ' behaviour on energy consumption investigated in 290 identical dwellings and in 35 apartments," in Healthy Buildings 2012, 2012, no. July, pp. 8-12.

[24] S. Wei, R. Jones, and P. De Wilde, "Driving factors for occupant-controlled space heating in residential buildings," Energy Build., vol. 70, pp. 36-44, 2014.

[25] B. Peter, "Consumers and domestic heating controls : a literature review," 2012.

[26] T. Kane, S. K. Firth, and K. J. Lomas, "How are UK homes heated? A city-wide, sociotechnical survey and implications for energy modelling," Energy Build., vol. 86, pp. 817-832, 2015.

[27] G. M. Huebner et al., "The shape of warmth: temperature profiles in living rooms," Build. Res. Inf., vol. 43, no. 2, pp. 185-196, 2015.

[28] World Health Organization, "Health impact of low indoor temperatures: Report on a WHO meeting," Copenhagen, Denmark, 1987.

[29] D. B. Belzer and K. A. Cort, "Statistical Analysis of Historical State-Level Residential Energy Consumption Trends," Prism, pp. 25-38, 2002.

[30] M. Pritoni, A. K. Meier, C. Aragon, D. Perry, and T. Peffer, "Energy efficiency and the misuse of programmable thermostats: The effectiveness of crowdsourcing for understanding household behavior," Energy Res. Soc. Sci., vol. 8, pp. 190-197, 2015.

[31] M. Shipworth, "Thermostat settings in English houses: No evidence of change between 1984 and 2007," Build. Environ., vol. 46, no. 3, pp. 635-642, 2011.

[32] O. Guerra-Santin and S. Silvester, "Development of Dutch occupancy and heating profiles for building simulation," Build. Res. Inf., vol. 45, no. 4, pp. 396-413, 2017.

[33] R. V. Andersen, B. W. Olesen, and J. Toftum, "Modelling occupants' heating set-point preferences," 12th Conf. Int. Build. Perform. Simul. Assoc. Sydney, 14-16 Novemb., pp. 151156, 2011.

[34] T. Kane, S. K. Firth, T. M. Hassan, and V. Dimitriou, "Heating behaviour in English homes: An assessment of indirect calculation methods," Energy Build., vol. 148, pp. 89-105, 2017.

[35] B. R. Anderson et al., BREDEM-8 Model Description: 2001 Update. Building Research Establishment (BRE), Garston, and Department for Environment, Food and Rural Affairs (DEFRA), London, 2002.

[36] G. M. Huebner, M. McMichael, D. Shipworth, M. Shipworth, M. Durand-Daubin, and A. Summerfield, "The reality of English living rooms - A comparison of internal temperatures against common model assumptions," Energy Build., vol. 66, pp. 688-696, 2013.

[37] S. K. Firth, K. J. Lomas, and A. J. Wright, "Targeting household energy-efficiency measures using sensitivity analysis," Build. Res. Inf., vol. 38, no. 1, pp. 24-41, 2010.

[38] G. Branco, B. Lachal, P. Gallinelli, and W. Weber, "Predicted versus observed heat consumption of a low energy multifamily complex in Switzerland based on long-term experimental data," Energy Build., vol. 36, no. 6, pp. 543-555, 2004.

[39] A. L. Lindén, A. Carlsson-Kanyama, and B. Eriksson, "Efficient and inefficient aspects of residential energy behaviour: What are the policy instruments for change?," Energy Policy, vol. 34, no. 14, pp. 1918-1927, 2006.

[40] R. Haas, H. Auer, and P. Biermayr, "The impact of consumer behavior on residential energy demand for space heating," Energy Build., vol. 27, no. 2, pp. 195-205, 1998. 
[41] T. Oreszczyn and R. Lowe, "Memorandum. House of Lords Select Committee on Science and Technology Minutes of Evidence," The Stationery Office, London, 2004.

[42] A. Beizaee, D. Allinson, K. J. Lomas, E. Foda, and D. L. Loveday, "Measuring the potential of zonal space heating controls to reduce energy use in UK homes: The case of un-furbished 1930s dwellings," Energy Build., vol. 92, pp. 29-44, 2015.

[43] J. Cockroft, A. Cowie, A. Samuel, and P. Strachan, "Potential energy savings achievable by zoned control of individual rooms in UK housing compared to standard central heating controls," Energy Build., vol. 136, pp. 1-11, 2017.

[44] K. Li, B. Lloyd, X. J. Liang, and Y. M. Wei, "Energy poor or fuel poor: What are the differences?," Energy Policy, vol. 68, pp. 476-481, 2014.

[45] J. Hills, "Getting the measure of fuel poverty - Final Report of the Fuel Poverty Review," London, 2012.

[46] “EnerGAware," 2016. [Online]. Available: http://www.energaware.eu/. [Accessed: 17-Oct2017].

[47] Office of National Statistics (ONS), "Census 2011: Key Statistics for local authorities in England and Wales," London, 2012.

[48] HM Government, Housing Act, 1996. United Kingdom, 1996.

[49] Ministry of Housing Communities \& Local Government, "Social and private renters: Demographic and economic data on social and private renters," 2017. [Online]. Available: https://www.gov.uk/government/statistical-data-sets/social-and-private-renters. [Accessed: 13Apr-2017].

[50] Building Research Establishment (BRE), "The Government's Standard Assessment Procedure for Energy Rating of Dwellings." [Online]. Available: https://www.bre.co.uk/filelibrary/SAP/2009/SAP-2009_9-90.pdf. [Accessed: 05-Jan-2018].

[51] DCLG, "English Housing Survey: Headline Report 2013-14," 2015.

[52] D. R. G. Hunt and M. I. Gidman, "A national field survey of house temperatures," Build. Environ., vol. 17, no. 2, pp. 107-124, 1982.

[53] J. S. Weihl and P. M. Gladhart, "Occupant behavior and successful energy conservation: Findings and implications of behavioral monitoring," 1990, pp. 171-180, 1990.

[54] R. Day and R. Hitchings, "Older people and their winter warmth behaviours: Understanding the contextual dynamics," p. 60, 2009.

[55] E. Sardianou, "Estimating space heating determinants: An analysis of Greek households," Energy Build., vol. 40, no. 6, pp. 1084-1093, 2008.

[56] G. M. Huebner, J. Cooper, and K. Jones, "Domestic energy consumption - What role do comfort, habit, and knowledge about the heating system play?," Energy Build., vol. 66, pp. 626-636, 2013.

[57] A. Meier et al., "How People Actually Use Thermostats," Control. Inf. Technol., vol. 2, pp. 193206, 2010.

[58] A. G. Munton, A. J. Wright, P. S. Mallaburn, and P. . Boait, "How heating controls affect domestic energy demand : A Rapid Evidence Assessment," London, 2014.

[59] M. M. Manning, M. C. Swinton, F. Szadkowski, J. Gusdorf, and K. Ruest, "The effects of thermostat setback and setup on seasonal energy consumption, surface temperatures, and recovery times at the CCHT twin house research facility," ASHRAE Trans., vol. 113 PART 1, pp. 630-641, 2007.

[60] J. Ingersoll and J. Huang, "Heating energy use management in residential buildings by temperature control," Energy Build., vol. 8, no. 1, pp. 27-35, 1985. 
[61] L. W. Nelson and M. . Ward, "Energy savings through thermostat setback," ASHRAE, vol. 9, pp. 49-54, 1978.

[62] Z. Liao, M. Swainson, and A. L. Dexter, "On the control of heating systems in the UK," Build. Environ., vol. 40, no. 3, pp. 343-351, 2005.

[63] M. J. Nevius and S. Pigg, "Programmable thermostats that go berserk? Taking a social perspective on space heating in Wisconsin," Proc. ACEEE Summer Study Energy Effic. Build., vol. 8, pp. 233-244, 2000.

[64] K. Lomas, D. Shipworth, A. Wright, and A. Summerfield, "Carbon Reduction in Buildings (CaRB)," in RICS Annual Conference Cobra, London, UK, 7-8 Sep 2006, 2006.

[65] K. Lomas et al., "4M: measurement; modelling; mapping and management - the carbon footprint of UK cities," in Low Carbon Cities: Proceedings of International Society of City and Regional Planners, The Hague, Netherlands, 2010, pp. 168-191.

[66] ISO, BSO EN ISO 13790: 2008, Energy Performance of Buildings - Calculation of Energy Use for Space Heating and Cooling. 2008. 